\title{
Coordination of physiological and structural traits in Amazon forest trees
}

\author{
S. Patiño ${ }^{1,2, \dagger}$, N. M. Fyllas ${ }^{2}$, T. R. Baker ${ }^{2}$, R. Paiva ${ }^{3}$, C. A. Quesada ${ }^{2-4}$, A. J. B. Santos ${ }^{3,4,}$, M. Schwarz ${ }^{1}$, \\ H. ter Steege ${ }^{5}$, O. L. Phillips ${ }^{2}$, and J. Lloyd ${ }^{2,6}$ \\ ${ }^{1}$ Max-Planck-Institut für Biogeochemie, Postfach 100164, 07701, Jena, Germany \\ ${ }^{2}$ School of Geography, University of Leeds, LS2 9JT UK \\ ${ }^{3}$ Institito Nacional de Pesquisas da Amazônia, Manaus, AM, Brazil \\ ${ }^{4}$ Departamento de Ecologia, Universidade de Brasília, DF, Brazil \\ ${ }^{5}$ Dept. of Plant Ecology and Biodiversity, Utrecht University, The Netherlands \\ ${ }^{6}$ School of Earth and Environmental Sciences, James Cook University, Cairns, Qld 4871, Australia \\ $\dagger$ deceased
}

Correspondence to: J. Lloyd (j.1loyd@leeds.ac.uk)

Received: 5 May 2011 - Published in Biogeosciences Discuss.: 25 May 2011

Revised: 16 November 2011 - Accepted: 18 January 2012 - Published: 16 February 2012

\begin{abstract}
Many plant traits covary in a non-random manner reflecting interdependencies associated with "ecological strategy" dimensions. To understand how plants integrate their structural and physiological investments, data on leaf and leaflet size and the ratio of leaf area to sapwood area $\left(\Phi_{\mathrm{LS}}\right)$ obtained for 1020 individual trees (encompassing 661 species) located in 52 tropical forest plots across the Amazon Basin were incorporated into an analysis utilising existing data on species maximum height $\left(H_{\max }\right)$, seed size, leaf mass per unit area $\left(M_{\mathrm{A}}\right)$, foliar nutrients and $\delta^{13} \mathrm{C}$, and branch xylem density $\left(\rho_{\mathrm{X}}\right)$.

Utilising a common principal components approach allowing eigenvalues to vary between two soil fertility dependent species groups, five taxonomically controlled trait dimensions were identified. The first involves primarily cations, foliar carbon and $M_{\mathrm{A}}$ and is associated with differences in foliar construction costs. The second relates to some components of the classic "leaf economic spectrum", but with increased individual leaf areas and a higher $\Phi_{\text {LS }}$ newly identified components for tropical tree species. The third relates primarily to increasing $H_{\max }$ and hence variations in light acquisition strategy involving greater $M_{\mathrm{A}}$, reductions in $\Phi_{\mathrm{LS}}$ and less negative $\delta^{13} \mathrm{C}$. Although these first three dimensions were more important for species from high fertility sites the final two dimensions were more important for low fertility species and were associated with variations linked to reproductive and shade tolerance strategies.

Environmental conditions influenced structural traits with $\rho_{\mathrm{x}}$ of individual species decreasing with increased soil fertility and higher temperatures. This soil fertility response
\end{abstract}

appears to be synchronised with increases in foliar nutrient concentrations and reductions in foliar [C]. Leaf and leaflet area and $\Phi_{\mathrm{LS}}$ were less responsive to the environment than $\rho_{\mathrm{X}}$.

Thus, although genetically determined foliar traits such as those associated with leaf construction costs coordinate independently of structural characteristics such as maximum height, others such as the classical "leaf economic spectrum" covary with structural traits such as leaf size and $\Phi_{\text {LS }}$. Coordinated structural and physiological adaptions are also associated with light acquisition/shade tolerance strategies with several traits such as $M_{\mathrm{A}}$ and [C] being significant components of more than one ecological strategy dimension. This is argued to be a consequence of a range of different potential underlying causes for any observed variation in such "ambiguous" traits. Environmental effects on structural and physiological characteristics are also coordinated but in a different way to the gamut of linkages associated with genotypic differences.

\section{Introduction}

Plant traits are widely used in ecology and biogeochemistry. In particular, sets of functional characters can serve as the basis for identifying important adaptations that improve the success of different taxa at different environments. Over the last decade significant advances have been made in terms of our understanding of plant trait inter-relationships and associated trade-offs (Reich et al., 1997; Westoby et al., 2002), 
especially in terms of the so called "leaf economic spectrum" (Wright et al., 2004) with well documented systematic and co-ordinated changes in leaf nitrogen and phosphorus concentrations, leaf mass per unit area, $M_{\mathrm{A}}$ and leaf lifetimes.

Attention has also been paid to the relationships between physiological and structural characteristics of leaves and other plant traits. For example, it has been reported that leaf size declines with wood density, $\rho_{\mathrm{w}}$ (Pickup et al., 2005; Wright et al., 2006, 2007; Malhado et al., 2009) and it has been suggested that this is because the ratio of leaf area to sapwood area $\left(\Phi_{\mathrm{LS}}\right)$ should also decline with increasing wood density due to hydraulic constraints (Wright et al., 2007). Nevertheless, although $\Phi_{L S}$ may decline with $\rho_{\mathrm{w}}$ for trees in some ecosystems that are clearly waterlimited (Ackerly, 2004; Cavender-Bares et al., 2004), $\Phi_{\mathrm{LS}}$ sometimes actually increases with $\rho_{\mathrm{w}}$ (Wright et al., 2006; Meinzer et al., 2008). The latter study also found that associated with these higher $\Phi_{L S}$ and high wood density stems were lower stem hydraulic conductances, more negative midday leaf water potentials, and more negative bulk leaf osmotic potentials at zero turgor. Thus, leaves of some high wood density species may be characterised by physiological and structural adaptations allowing them to function at more severe water deficits than is the case for low wood density species.

The Panama study of Meinzer et al. (2008) also found that higher $\rho_{\mathrm{w}}$ species tended to have higher $M_{\mathrm{A}}$. Although similar positive correlations between $M_{\mathrm{A}}$ and $\rho_{\mathrm{w}}$ have also been reported for other ecosystems (e.g. for sclerophyllous forest: Ishida et al., 2008) when examining the bivariate relationship between $\rho_{\mathrm{w}}$ and $M_{\mathrm{A}}$ across a range of tropical forest sites, Wright et al. (2007) observed no significant relationship. Likewise, when examining variation in leaf and stem traits for 17 dipterocarp species growing in a common garden in southern China, Zhang and Cao (2009) also found no significant correlation between $\rho_{\mathrm{w}}$ and $M_{\mathrm{A}}$.

Variations in $M_{\mathrm{A}}$ may also be related to a suite of additional plant physiological characteristics (Poorter et al., 2009), varying negatively with dry-weight foliar nitrogen and phosphorus concentrations (Wright et al., 2004; Fyllas et al., 2009) as well as tending to increase with increasing tree height (Thomas and Bazzaz, 1999; Kenzo et al., 2006; Lloyd et al., 2010). Potential tree height, $H_{\max }$, has also been related to a number of wood traits (Chave et al., 2009) with taller plants tending to have bigger conduits in their trunks, but fewer conduits overall (Coomes et al., 2007).

Within a given stand, taller and generally more lightdemanding rain forest species also tend to have larger leaves, this being associated with shallower crown and a more efficient light capture (Poorter et al., 2006; Poorter and Rozendaal, 2008). Leaf-size may also be influenced by other factors. For example, Australian rain forests growing on oligotrophic soils typically have a greater abundance of smaller leaved species than for nearby forests found on more mesotrophic soil types (Webb, 1968).
Seed size may also relate to the above plant functional traits. For example, one of "Corner's rules" describes a tendency for species with thick twigs to have large appendages (leaves and fruit). The range of viable seed size also tends to increase with plant height (Moles et al., 2005; Grubb et al., 2005). Forests on the more fertile soils of western Amazonia tend to have smaller average seed masses than their less fertile counterparts on the Guyana Shield and elsewhere (ter Steege et al., 2006), this perhaps being related to several advantages attributable to large seeded species under nutrientpoor conditions, viz. greater initial nutrient stores, greater initial root zone expansion, and increased mychorrizal infection, all of which would be expected to increase the probability of seedling survival (Foster, 1986).

This paper presents new data on leaf and leaflet size and $\Phi_{\mathrm{LS}}$ for 661 species located in 52 plots across the Amazon Basin. The trees sampled form a subset of those also examined for variations in branch xylem density (Patiño et al., 2009), and for foliar nutrients, $M_{\mathrm{A}}$ and $\delta^{13} \mathrm{C}$ (Fyllas et al., 2009), which had previously been analysed separately. We here investigate the inter-relationships between these structural and physiological parameters also considering taxonomic variations in $H_{\max }$ (Baker et al., 2009) and seed mass (ter Steege and Hammond, 2001; ter Steege et al., 2006). Specifically, we were interested to assess the degree to which the observed variations in the studied structural and physiological traits were coordinated with each other into identifiable integrated trait dimensions: for example, those associated with leaf construction costs, light acquisition, and/or shade tolerance.

\section{Materials and methods}

\subsection{Study sites}

In the analysis here, RAINFOR sample plots have been aggregated as discussed in Fyllas et al. (2009), with further plot details available in Patiño et al. (2009) and Quesada et al. (2010). Ten plots in Fyllas et al. (2009) have not been included due to insufficient structural trait data having been collected, but the range of soils encountered here is still substantial with the sum of exchangeable bases $(0-$ $0.3 \mathrm{~m}$ ), for example ranging from less than $1 \mathrm{mmol}_{\mathrm{c}} \mathrm{kg}^{-1}$ to nearly $100 \mathrm{mmol}_{\mathrm{c}} \mathrm{kg}^{-1}$. Total soil phosphorus ranged from $26 \mathrm{mg} \mathrm{kg}^{-1}$ for an ortseinc podzol to $727 \mathrm{mg} \mathrm{kg}^{-1}$ for a eutric cambisol (Quesada et al., 2010). Mean annual precipitation varies from less than $1.5 \mathrm{~m} \mathrm{a}^{-1}$ on sites at the north and southern periphery of the basin to more than $3.0 \mathrm{~m} \mathrm{a}^{-1}$ for sub-montane sites close to the Andes. 


\subsection{Structural traits}

For most trees sampled in Patiño et al. (2009) and Fyllas et al. (2009), and from the same terminal branches for which data has already been presented in those studies, all leaves from the branch had also been counted. From that branch, a sub-sample of 10-20 leaves was randomly chosen to estimate individual leaf area, $L_{\mathrm{A}}$, and leaflet area, $\ell_{\mathrm{A}}$ (when a species had compound leaves), and to estimate the total leaf area of the branch. All age and size leaves or leaflets were selected for this analysis except for very young leaves or those which were obviously senescent. The chosen leaves were usually scanned fresh on the same day of collection. When this was not possible the same day, they were stored for a maximum of two days in sealed plastic bags to avoid desiccation and any consequent reduction of the leaf area. Scans were analysed using "Win Folia Basic 2001a" (Regent Instruments Inc., 4040 rue Blain Quebec, QC., G2B 5C3 Canada) to obtain $L_{\mathrm{A}}$ and $\ell_{\mathrm{A}}$.

The distal (sapwood + pith) and pith diameters for each branch were also measured with a digital caliper (Mitutoyo Corporation, Japan) with sapwood area, $A_{\mathrm{S}}$, then estimated by subtracting pith area from the total branch area with $\Phi_{\mathrm{LS}}=n \bar{L}_{\mathrm{A}} / A_{\mathrm{S}}$ where $n$ is the number of leaves distal to the piece of branch sampled and $\bar{L}_{\mathrm{A}}$ is the average area of the individual leaves sub-sampled for the estimation of $L_{\mathrm{A}}$ and/or $\ell_{\mathrm{A}}$.

Branch xylem density data for the same samples were obtained as described in Patiño et al. (2009). In brief, this consisted of the estimation of the volume of a branch segment, approximately $1 \mathrm{~cm}$ in diameter and $5-10 \mathrm{~cm}$ long using calipers, with the pith removed as necessary and dry weight subsequently determined. Species maximum height taken from the database developed by Baker et al. (2009) with estimates made to the species level for $80 \%$ of the trees identified, and the bulk of the remainder being genus level averages. Seed mass $(S)$ was taken as a genus level dependent variable and was already on a $\log _{10}$ ordinal scale (ter Steege et al., 2006).

\subsection{Physiological foliar traits}

Foliar traits used here are as described/measured in Fyllas et al. (2009) and Lloyd et al. (2010) and include leaf mass per unit area $\left(M_{\mathrm{A}}\right)$ and foliar $[\mathrm{N}],[\mathrm{C}],[\mathrm{P}],[\mathrm{Ca}],[\mathrm{K}]$ and $[\mathrm{Mg}]$ expressed on dry-weight basis. Foliar ${ }^{13} \mathrm{C} /{ }^{12} \mathrm{C}$ discrimination, $\Delta$, was estimated from measurements of foliar $\delta^{13} \mathrm{C}$ (Fyllas et al., 2009) using an assumed value for the isotopic composition of source air equal to $-8.0 \%$ (Farquhar et al., 1989) and subsequently transformed to a diffusional limitation index, $\oslash$, according to (Fyllas et al., 2012)

$\oslash=1-\sqrt{\frac{(\Delta-4.4) / 25.6-0.2}{0.8}}$ which utilises the well known relationship between $\Delta$ and the ratio of internal to ambient $\mathrm{CO}_{2}$ concentrations, $c_{\mathrm{i}} / c_{\mathrm{a}}$ (Farquhar et al., 1989). Equation (1) assumes that at current day $c_{\mathrm{a}}$, photosynthesis can be considered a roughly linear function of $c_{\mathrm{i}}$ and with a maximum practical $c_{\mathrm{i}} / c_{\mathrm{a}}$ (indicating minimal diffusional limitation) of 0.8. Here we have taken a value of $4.4 \%$ for the fractionation against ${ }^{13} \mathrm{CO}_{2}$ during diffusion into the leaf and $30.0 \%$ of the fractionation against ${ }^{13} \mathrm{CO}_{2}$ during photosynthetic fixation (Farquhar et al., 1989). Increasing $\oslash$ values are associated with lower $c_{\mathrm{i}} / c_{\mathrm{a}}$, and thus, other things being equal, a higher water use efficiency, $W$, this being the ratio of carbon gained to water lost during photosynthetic $\mathrm{CO}_{2}$ assimilation. Equation (1) relies on a simplified expression for $\Delta$ which ignores difference between gas- and liquid-phase fractionations within the leaf (Farquhar et al., 1989), but this should not seriously compromise its utility in the current context.

\subsection{Climate and soils}

The soil and climate predictors table used was the same as in Fyllas et al. (2009), using a set of measured soil properties (Quesada et al., 2010) with precipitation variables and temperature from the "WorldClim" dataset (http://www. worldclim.org). Estimates of mean annual solar radiation are from New et al. (2002). As in Fyllas et al. (2009) we separate soils into two fertility classes based on their total phosphorus concentration and the total sum of reserve bases, (Quesada et al., 2010). In brief this categorisation gives rise to arenosols, podzols, ferralsols, and most acrisols being classified as low fertility soils. High fertility soils include plinthosols, cambisols, fluvisols, gleysols and most alisols.

\subsection{Statistical analysis}

This paper implements a similar set of statistical analyses to that described in detail in Fyllas et al. (2009). Preliminary tests included analysis of normality (Shapiro-Wilk) and homogeneity of variance (Fligner-Killeen) for each of the structural traits of interest. The foliar related structural traits $\left(L_{\mathrm{A}}\right.$, $\ell_{\mathrm{A}}$ and $\left.\Phi_{\mathrm{LS}}\right)$ presented a right skewed distribution and thus were all $\log _{10}$ transformed. As $\rho_{\mathrm{x}}, H_{\max }$ and $S$ (the latter already provided as size classes on a $\log _{10}$ scale) were more or less symmetrically distributed around their mean we did not apply this transformation for these variables, even though the Shapiro test failed to identify strict normality. The nonparametric Kruskal-Wallis test (Hollander and Wolfe, 1999) was used to explore for differences between fertility groups as well as for differences between families, genera within a family and species within a genus. All analyses were performed with the $\mathrm{R}$ statistical platform (R Development Core Team, 2010). 


\subsubsection{Partitioning of variance and estimation of taxonomic and environmental effects}

A multilevel model was initially fitted for all traits (including those previously analysed separately in Fyllas et al. (2009) and Patiño et al. (2009) because this was a slightly different dataset), except $H_{\max }$ and $S$ according to

$\Theta=\mu+p+f / g / s+\epsilon$,

where $\mu$ is the overall mean value of each trait, $\Theta ; p$ is the plot effect, i.e. the effect of the location that each individual is found, and $f / g / s$ represents the genetic structure of the data, i.e. that each individual belongs to a species $(s)$, nested in a genus $(g)$, nested in a family $(f)$, and $\epsilon$ is the error term. All parameters were estimated by the Residual Maximum Likelihood (REML) method with the lme4 library available within R (Bates and Sarkor, 2007). Fyllas et al. (2009) have already discussed further details of the above formulations and the advantage in being able to partition the variance from the family to the species level, also taking into account the location (thus the environmental contribution to trait variation) where the trait was measured. The Supplementary Information (II) of that paper also provides an empirical validation of the approach used. Note, that whilst theoretically possible, we do not include interaction terms in Eq. (2), this is because there is insufficient species replication across different sites. Nevertheless, investigations into the likely magnitude of such effects have been undertaken as part of the analyses in both Patiño et al. (2009) and Fyllas et al. (2009) and have not been found to be significant. Again we were interested in exploring the taxonomic (estimated as the sum of family \pm genus \pm species random effects) and environmental terms, using bivariate relationships as well as multiple nonparametric regressions of plot effect contributions on a set of environmental predictors. For the latter we used Kendall's $\tau$ as our measure of association calculating the significance of partial correlations using our own specifically written code, using the R statistical platform.

For $H_{\max }$ and $S$ no multilevel model was fitted or environmental effect assumed, the available data being considered to express directly the genetic potential of each species. We also note that our estimates of $S$ are resolved at the genus level only (ter Steege and Hammond, 2001) and are only on a $\log _{10}$ categorical scale. This introduces potential errors into the analyses where $S$ is involved because all other traits have been resolved at the species level. Thus, even though a small portion of the observed variation in $S$ generally occurs at the species level (Casper et al., 1992), bivariate and multivariate analyses involving this trait as presented here may carry somewhat more "noise" than would otherwise be the case.

\subsubsection{Bivariate relationships}

Relationships were initially assessed with the Pearson's correlation coefficient $(r)$ with subsequent Standardized Ma- jor Axis (SMA) line fits where significant correlations were identified. In this study, SMA line fits are applied to the raw dataset (including all measured traits and thus intraspecific variation), to the taxonomic component of trait variation (i.e. each species is represented by a single data point) as well as to the plot level effects (i.e. each plot is contributing a single data point). In each case we initially fitted separate lines for each fertility group, and when a common SMA slope was identified we tested for differences in elevation and/or slope between fertility groups, using the smartr library available within R (Warton et al., 2006).

We explored the plot level effect of each structural trait, through non-parametric correlation analysis on selected soil and environmental predictors, with the soil variables reduced to three principal axes to avoid multicollinearity (Fyllas et al., 2009). The climatic variables of mean annual temperature, total annual precipitation, dry season precipitation and mean annual radiation were also examined. As extensively discussed in Fyllas et al. (2009) we dealt with spatial autocorrelation issues by fitting appropriate simultaneous autoregressive models (SAR) which include a spatial error term (Lichstein et al., 2002) to help interpret the significance of full and partial Kendall's $\tau$ coefficients as a measure of association between plot-level trait effects and environmental predictors.

\subsubsection{Multivariate analyses}

Inferred taxonomic effects were analysed jointly for species found on fertile versus infertile soils (excluding those found on both soil types) by calculating separate variancecovariance matrices for the two species groups and then using the common principal components (CPC) model of Flury (1988) as implemented by Phillips and Arnold (1999). Within this model, it is assumed that the two populations of species have the same eigenvectors (principal components; denoted here as $U$ ) but that the relative loading of the various $U$ as expressed through their eigenvalues $(\lambda)$ may potentially vary between the two populations. Flury's model provides a hierarchy of tests corresponding to a range of possible relationships between matrices including equality, proportionality, common principal components, partial common principal components or unrelated (Flury, 1988; Phillips and Arnold, 1999). CPC can thus be seen as a method for summarizing the variation in two or more matrices. Nevertheless, caution needs to be applied when using CPC to address the more complex goal of diagnosing and understanding the nature of the changes that underlie the difference between the matrices. This is because CPC tends to spread any differences over many of the vectors it extracts and often over all of them (Houle et al., 2002).

As the CPC model does not strictly apply to correlation matrices (Flury, 1988), we standardised each variable before calculating the input variance-covariance matrix by dividing each variable by its observed range (across both high and 

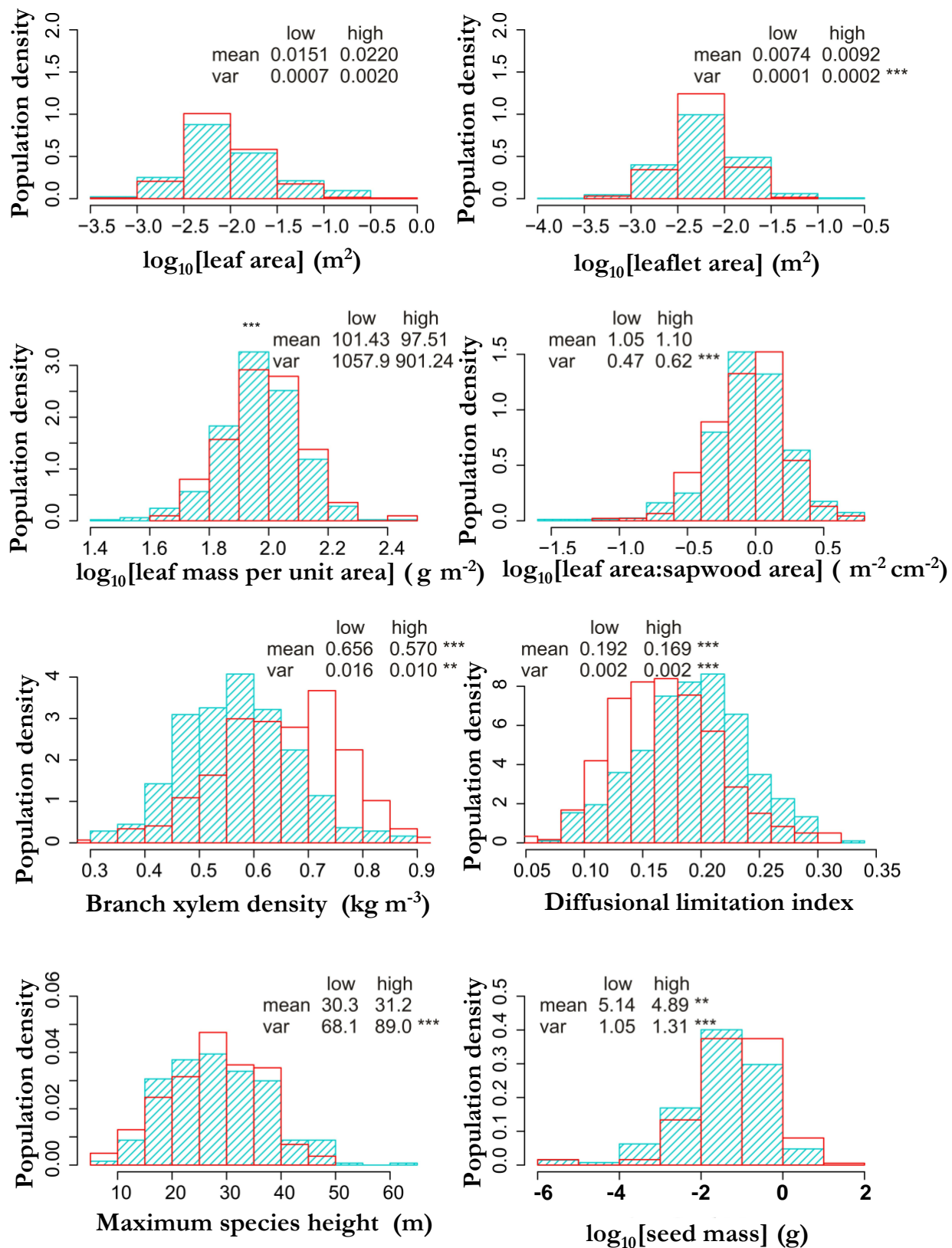

Fig. 1. Probability density histograms of raw data per fertility group for leaf area $\left(L_{\mathrm{A}} ; \mathrm{m}^{2}\right)$, leaflet area $\left(\ell_{\mathrm{A}} ; \mathrm{m}^{2}\right)$, leaf mass per unit area $\left(M_{\mathrm{A}} ; \mathrm{g} \mathrm{m}^{-2}\right),\left(\mathrm{m}^{2}\right)$, leaf area:sapwood area ratio $\left(\Phi_{\mathrm{LS}} ; \mathrm{cm}^{2} \mathrm{~m}^{-2}\right)$, branch xylem density $\left(\rho_{\mathrm{x}} ; \mathrm{kg} \mathrm{m}^{-3}\right), \oslash=$ stomatal limitation index (dimensionless; see Eq. 1$)$, species maximum height $\left(H_{\text {max }} ; \mathrm{m}\right)$ and seed mass $(S ; \mathrm{g})$. Open red bars represent low and blue dashed bars high soil fertility plots, as defined by the quantitative determinations of the level of total reserve bases from 0.0-0.3 m depth (Fyllas et al., 2009; Quesada et al., 2010). Also given for each histogram are the mean and the variance for each trait. Significant differences in mean values and/or variances between the two fertility groups were identified with the Fligner-Killeen test respectively. Significance codes: $* * *<0.001$, $* *<0.01, *<0.05$.

low fertility soils) as first proposed by Gower (1966) but, due to the presence of the occasional outlier, taking the effective range as the 0.1 to 0.9 quantiles. Standard errors of the $U$ and $\lambda$ for the CPC models were estimated assuming asymptotic normality as described in Flury (1988).
All other multivariate analyses (e.g. PCA of the derived environmental effects) were implemented with the ade 4 package (Thioulouse et al., 1997) available within the $R$ statistical platform with the environmental effect PCA undertaken on the correlation matrix. 


\section{Results}

\subsection{Trait distribution in relation to soil type}

The structural traits distributions along with those for $M_{\mathrm{A}}$ and $\oslash$ for the complete dataset divided to low and high fertility groups are shown in Fig. 1 with overall mean values, range and variances for each plot for all traits also provided in the Supplementary Information (Table S1). The three leaf related traits introduced here $\left(L_{\mathrm{A}}, \ell_{\mathrm{A}}\right.$ and $\left.\Phi_{\mathrm{LS}}\right)$ did not differ significantly between low and high fertility sites (Fig. 1). On the other hand, $\rho_{\mathrm{x}}$ and $S$ showed significant differences between the two fertility groups, with their distributions shifted to the left for fertile sites, i.e. higher $\rho_{\mathrm{x}}$ and $S$ were found for species found on infertile soils. This is similar to the shifted distributions identified for most leaf mineral concentrations across fertility gradients (Fyllas et al., 2009) but in the opposite direction, i.e. with higher structural carbon and lower mineral investment in less fertile environments. As expected from our prior analysis of the statistical distribution of foliar $\delta^{13} \mathrm{C}$ (Fyllas et al., 2009), the diffusional limitation index of Eq. $1 \oslash$ tended to be lower for trees growing on low fertility soils. Despite a difference in variance between low and high fertility sites, there was, however, no overall effect of soil fertility classification on the average $H_{\max }$.

\subsection{Partitioning of the variance}

The variation apportioned to different taxonomic levels varies for each of the traits examined (Fig. 2). When leaf size was expressed per leaflet, most of the variation was attributed at the species level (0.31) with the overall taxonomic component (i.e. family \pm genus \pm species) adding up to a very high (0.62) proportion. When leaf size was expressed at the leaf level, most of the variation was attributed at the family level $(0.29)$ with a very high overall taxonomic component $(0.71)$. In contrast to $L_{\mathrm{A}}$ and $\ell_{\mathrm{A}}$, plot level contributions to the total variance were substantial for the other structural traits: being around 0.30 for $\rho_{\mathrm{x}}$ and 0.27 for $\Phi_{\mathrm{LS}}$. These are not necessarily higher than their respective taxonomic components, but underline the importance of the site growing conditions in influencing structural traits such as $\rho_{\mathrm{x}}$ and $\Phi_{\mathrm{LS}}$. As for the foliar traits reported in Fyllas et al. (2009) this must have direct implications for different physiological processes. In that study, leaf mass per unit area and $[\mathrm{C}],[\mathrm{N}]$ and $[\mathrm{Mg}]$ emerged as highly constrained by the taxonomic affiliation, but with others, such as $[\mathrm{P}],[\mathrm{K}]$ and $[\mathrm{Ca}]$ also strongly influenced by site growing conditions. That study also found foliar $\delta^{13} \mathrm{C}$ to be strongly influenced by site growing conditions, consistent with its analogue here $(\oslash)$ having its environmental component as the dominant source for its variation. Overall, there was a tendency for the residual component (related to intraspecies variations not accountable for by different plot locations and experimental error) to increase as the proportion of variation accountable for by taxonomic affiliation declined

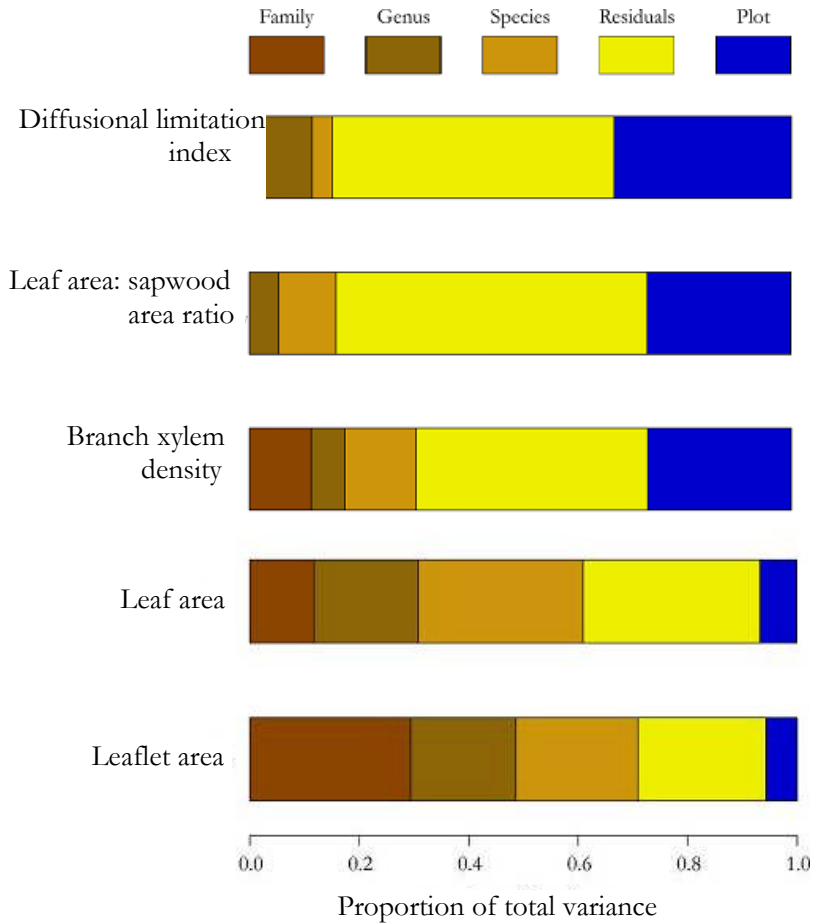

Fig. 2. Partitioning of the total variance for each studied property into taxonomic (family/genus/species), environmental (plot) and error (residual) components. Traits are sorted from less to more taxonomically constrained. Significance of each variance component was tested with a likelihood ratio test (Galwey, 2006). Significance codes: $* * *<0.001, * *<0.01, *<0.05$.

and with the proportion attributable to plot location tending to increase as the residual component became larger.

\subsection{Bivariate relationships: raw data}

These are not considered in any detail here, but for the interested reader data are summarised in the Supplementary Information, Table S2A.

\subsection{Bivariate relationships: taxonomic components}

Considering data from both low and high fertility sites together, Table 1 lists correlations and SMA slopes for the derived taxonomic components with this same information shown in more detail (including confidence intervals) in the Supplementary Information (Table S2A) and with low and high fertility species separated for OLS and SMA regression analyses in Table S2B. Within Table 1, the SMA slopes reflect the relationship $y \leftrightarrow x$, with the $x$ as the column headers and the $y$ being the row labels. Figures 3 through 6 illustrate the more important relationships involving the sampled structural traits. Due to considerations associated with multiple testing, we focus only on relationships significant 
Table 1. Relationships between the derived genetic components of the observed plant traits: $M_{\mathrm{A}}=$ leaf mass per unit area $\left(\mathrm{gm}^{-2}\right)$; elemental concentrations are on a dry weight basis $\left(\mathrm{mgg}^{-1}\right), L_{\mathrm{A}}=$ leaf area $\left(\mathrm{m}^{2}\right), \ell_{\mathrm{A}}=$ leaflet area $\left(\mathrm{m}^{2}\right), \Phi_{\mathrm{LS}}=$ leaf area:sapwood area ratio $\left(\mathrm{cm}^{2} \mathrm{~g}^{-1}\right), \rho_{\mathrm{x}}=$ branch xylem density $\left(\mathrm{kg} \mathrm{m}^{-3}\right), \oslash=$ stomatal limitation index (see Eq. 1$), S=$ seed mass $(\mathrm{g}), H_{\text {max }}=$ species maximum height $(\mathrm{m})$. Values above the diagonal represent the slope of the relationship (y axis as columns labels, $\mathrm{x}$ axis as row labels). Values below the diagonal represent the correlation coefficient. Values significant at $P<0.05$ are given in bold. NS $=$ no slope estimated as the relationship was not significant.

\begin{tabular}{|c|c|c|c|c|c|c|c|c|c|c|c|c|c|c|}
\hline Variable & $M_{\mathrm{A}}$ & {$[\mathrm{C}]$} & $\log [N]$ & $\log [\mathrm{P}]$ & $\log [\mathrm{Ca}]$ & $\log [\mathrm{K}]$ & $\log [\mathrm{Mg}]$ & $\log \left(L_{\mathrm{A}}\right)$ & $\log \left(\ell_{\mathrm{A}}\right)$ & $\log \left(\Phi_{L S}\right)$ & $\rho_{\mathrm{X}}$ & $\theta$ & $\log (S)$ & $H_{\max }$ \\
\hline $\log \left(M_{\mathrm{A}}\right)$ & - & 0.37 & -1.01 & -1.21 & NS & -1.65 & -2.18 & NS & 4.32 & -1.27 & 0.88 & NS & 19.2 & 167 \\
\hline$[\mathrm{C}]$ & 0.15 & - & NS & NS & -6.28 & -4.43 & $-\mathbf{5 . 8 5}$ & 17.30 & NS & NS & NS & NS & 51.4 & NS \\
\hline $\log [\mathrm{N}]$ & -0.43 & 0.07 & - & 1.20 & NS & 1.63 & NS & 6.36 & -4.18 & 1.22 & NS & 0.22 & -18.6 & NS \\
\hline $\log [\mathrm{P}]$ & -0.41 & -0.02 & 0.66 & - & 1.93 & 1.36 & 1.79 & 5.37 & NS & 1.03 & -0.72 & 0.19 & NS & NS \\
\hline $\log [\mathrm{Ca}]$ & -0.07 & -0.51 & 0.02 & 0.14 & - & 0.7 & 0.93 & NS & NS & NS & -0.37 & 0.10 & -8.3 & NS \\
\hline $\log [\mathrm{K}]$ & -0.28 & -0.45 & 0.18 & 0.46 & 0.46 & - & 1.32 & NS & 2.60 & NS & -0.52 & NS & -11.4 & NS \\
\hline $\log [\mathrm{Mg}]$ & -0.14 & -0.45 & 0.05 & 0.18 & 0.65 & 0.59 & - & -2.98 & 1.97 & NS & -0.40 & 0.10 & -8.8 & NS \\
\hline $\log \left(L_{\mathrm{A}}\right)$ & -0.09 & 0.14 & 0.27 & 0.37 & -0.03 & -0.01 & -0.14 & - & 0.65 & 0.19 & -0.13 & 0.04 & NS & NS \\
\hline $\log \left(\ell_{\mathrm{A}}\right)$ & 0.17 & -0.08 & -0.11 & 0.04 & 0.07 & 0.18 & 0.15 & 0.41 & - & NS & -0.2 & NS & NS & NS \\
\hline $\log \left(\Phi_{L S}\right)$ & -0.24 & 0.06 & 0.20 & 0.14 & 0.00 & 0.04 & -0.09 & 0.26 & 0.01 & - & NS & NS & NS & NS \\
\hline$\rho_{\mathrm{x}}$ & 0.13 & 0.07 & -0.08 & -0.20 & -0.21 & -0.24 & -0.12 & -0.10 & -0.22 & 0.07 & - & NS & 21.6 & NS \\
\hline$\oslash$ & 0.09 & 0.03 & 0.23 & 0.27 & 0.12 & 0.06 & 0.09 & 0.12 & -0.08 & -0.08 & -0.09 & - & -81.8 & 731 \\
\hline $\log (S)$ & 0.12 & 0.18 & -0.16 & -0.08 & -0.34 & -0.23 & -0.25 & 0.02 & 0.00 & -0.10 & 0.25 & -0.20 & - & 8.8 \\
\hline$H_{\max }$ & 0.17 & 0.04 & -0.03 & 0.00 & -0.06 & -0.02 & -0.08 & -0.02 & 0.00 & -0.07 & -0.03 & 0.11 & 0.14 & - \\
\hline
\end{tabular}

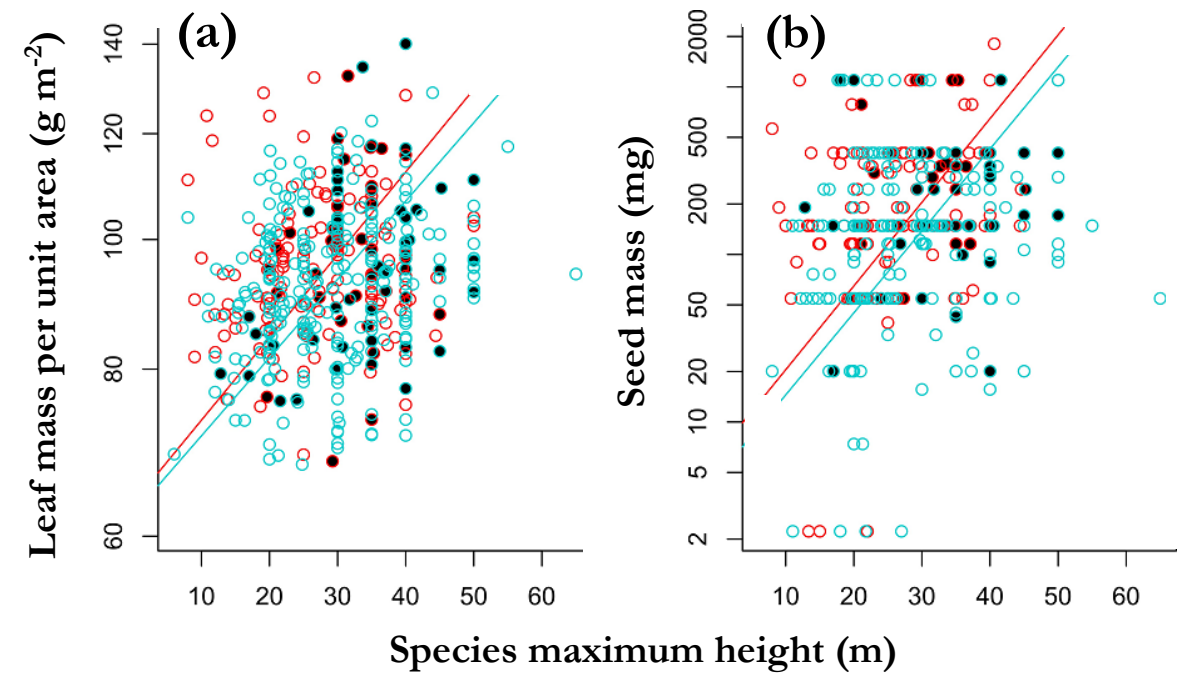

Fig. 3. Standard Major Axis (SMA) regression lines between species maximum height $\left(H_{\max }\right)$ and the derived taxonomic components of leaf mass per unit area $\left(M_{\mathrm{A}}\right)$ for the same species and the associated average seed mass $(S)$ for the associated genus. Red open circles indicate species found on low fertility sites and the blue open circles indicate species found on high fertility sites. Species found on both soil fertility groups are indicated with closed circles (see text for details). Red solid lines show the SMA model fit for low fertility species which is significantly different to the blue solid lines for high fertility soil species.

at $p \leq 0.001$ though, where interesting and/or informative, statistically less significant relationships are also considered.

\subsubsection{Maximum tree height}

Generally only poor correlations were observed for $H_{\max }$, these being significant only for $\log _{10}\left(M_{\mathrm{A}}\right)(p \leq 0.001)$ and $\log _{10}(S)(p \leq 0.01)$. The $M_{\mathrm{A}} \leftrightarrow H_{\max }$ and $S \leftrightarrow H_{\max }$ relationships are shown in Fig. 3. Here, due to differences in the
SMA slope and/or intercept between the species associated with the two soil fertility classes (see Supplementary Information, Table S2B) we have fitted separate lines for species found on low and high fertility soils. This shows that for species associated with low fertility soils, both $M_{\mathrm{A}}$ and $S$ tend to be slightly higher at a given $H_{\max }$ than their higher fertility counterparts. Especially for $S \leftrightarrow H_{\max }$ the variation is considerable, particularly at low $H_{\max }$, with $S$ varying three orders of magnitude for $H_{\max }$ between 10 and $30 \mathrm{~m}$. 

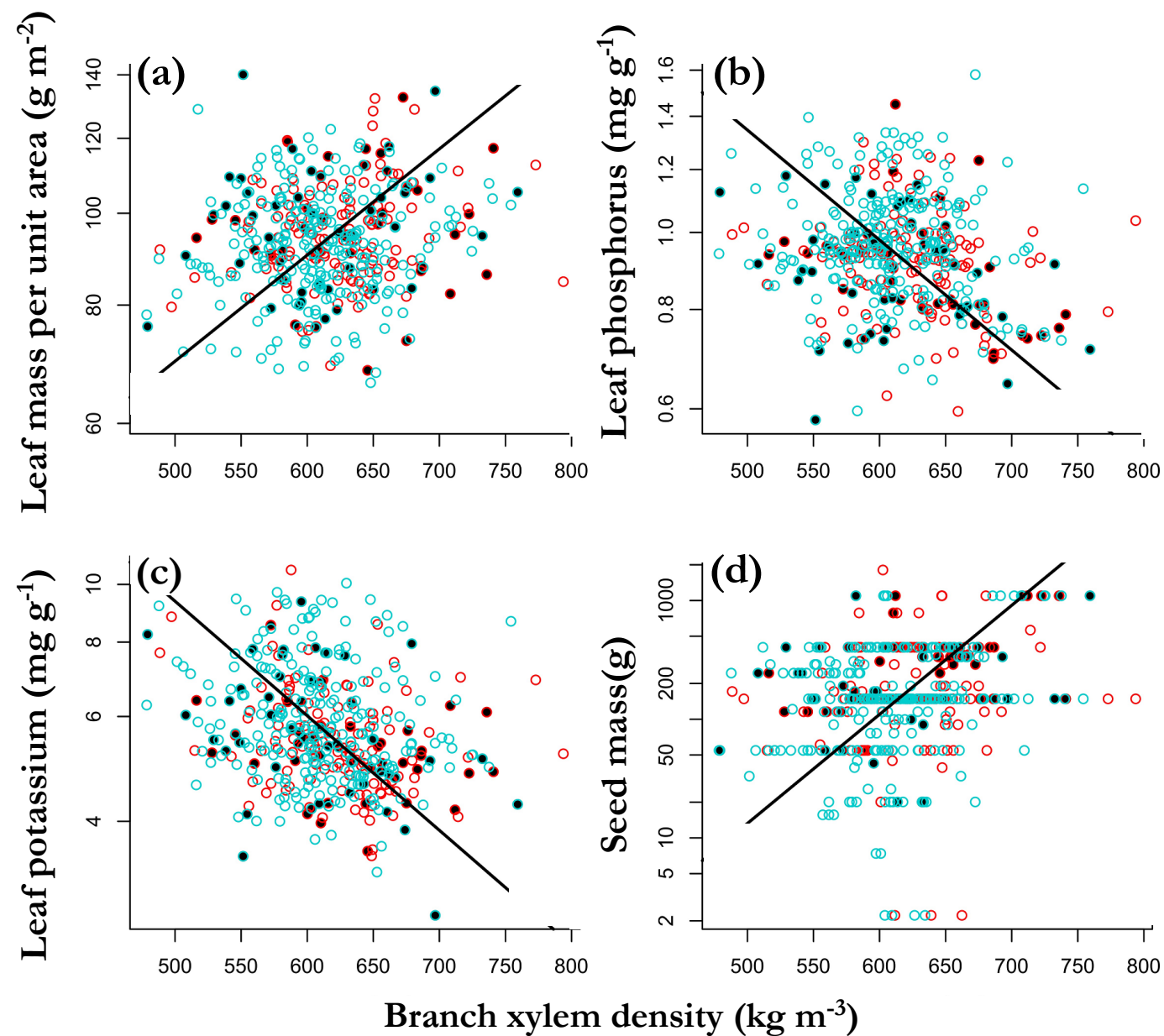

Fig. 4. Standard Major Axis (SMA) regression lines between the derived species components of branch xylem density ( $\left.\rho_{\mathrm{X}}\right)$ and those for mass per unit area $\left(M_{\mathrm{A}}\right)$, foliar $[\mathrm{P}]$ and foliar $[\mathrm{K}]$ for the same species and the average seed mass $(\mathrm{S})$ for the associated genus. Red open circles indicate species found on low fertility sites and the blue open circles indicate species found on high fertility sites. Species found on both soil fertility groups are indicated with closed circles (see text for details). The black solid lines show the SMA model fit which did not depend on soil fertility.

\subsubsection{Branch xylem density}

As detailed in Table 1, the derived taxonomic component of $\rho_{\mathrm{x}}$ was negatively correlated with $\log _{10}[\mathrm{P}], \log _{10}[\mathrm{Ca}]$, $\log _{10}[\mathrm{~K}], \log _{10}\left(\ell_{\mathrm{A}}\right)$ and positively associated with $\log _{10}(S)$ $(p \leq 0.001)$. A weaker but significant positive correlation was also observed with $\log _{10}\left(M_{\mathrm{A}}\right)$ and a negative correlation with $\log _{10}[\mathrm{Mg}](p \leq 0.01)$. Of minor significance was a negative association with $\log _{10}\left(L_{\mathrm{A}}\right)(p \leq 0.05)$. Some of these relationships are illustrated in Fig. 4 which shows the relationships between $\rho_{\mathrm{x}}$ and both $[\mathrm{P}]$ and $[\mathrm{K}]$ to be particularly compelling and, as is also the case for $M_{\mathrm{A}}$ and $S$, with no difference for species associated with low versus high fertility soils.

\subsubsection{Leaf area: sapwood area ratio}

Reasonably strong correlations were found for $\log _{10}\left(\Phi_{\mathrm{LS}}\right)$ with $\log _{10}\left(M_{\mathrm{A}}\right), \log _{10}[\mathrm{~N}]$ and $\log _{10}\left(L_{\mathrm{A}}\right)(p \leq 0.001)$ with the relationship between $\log _{10}\left(\Phi_{\mathrm{LS}}\right)$ and $\log _{10}[\mathrm{P}]$ also significant $(p \leq 0.01)$. The relevant biplots are shown in Fig. 5 . The slope for the taxonomic component $M_{\mathrm{A}} \leftrightarrow \Phi_{\mathrm{LS}}$ relationship is $1 /-1.27=-0.79$. Thus, as $\Phi_{\mathrm{LS}}$ increases across species, then $M_{\mathrm{A}}$ declines proportionally less. That is to say, species with a higher $\Phi_{\mathrm{LS}}$ also tend to carry a greater weight of (generally larger) leaves per unit stem area with those leaves also tending to have higher foliar $[\mathrm{N}]$ and $[\mathrm{P}]$. 

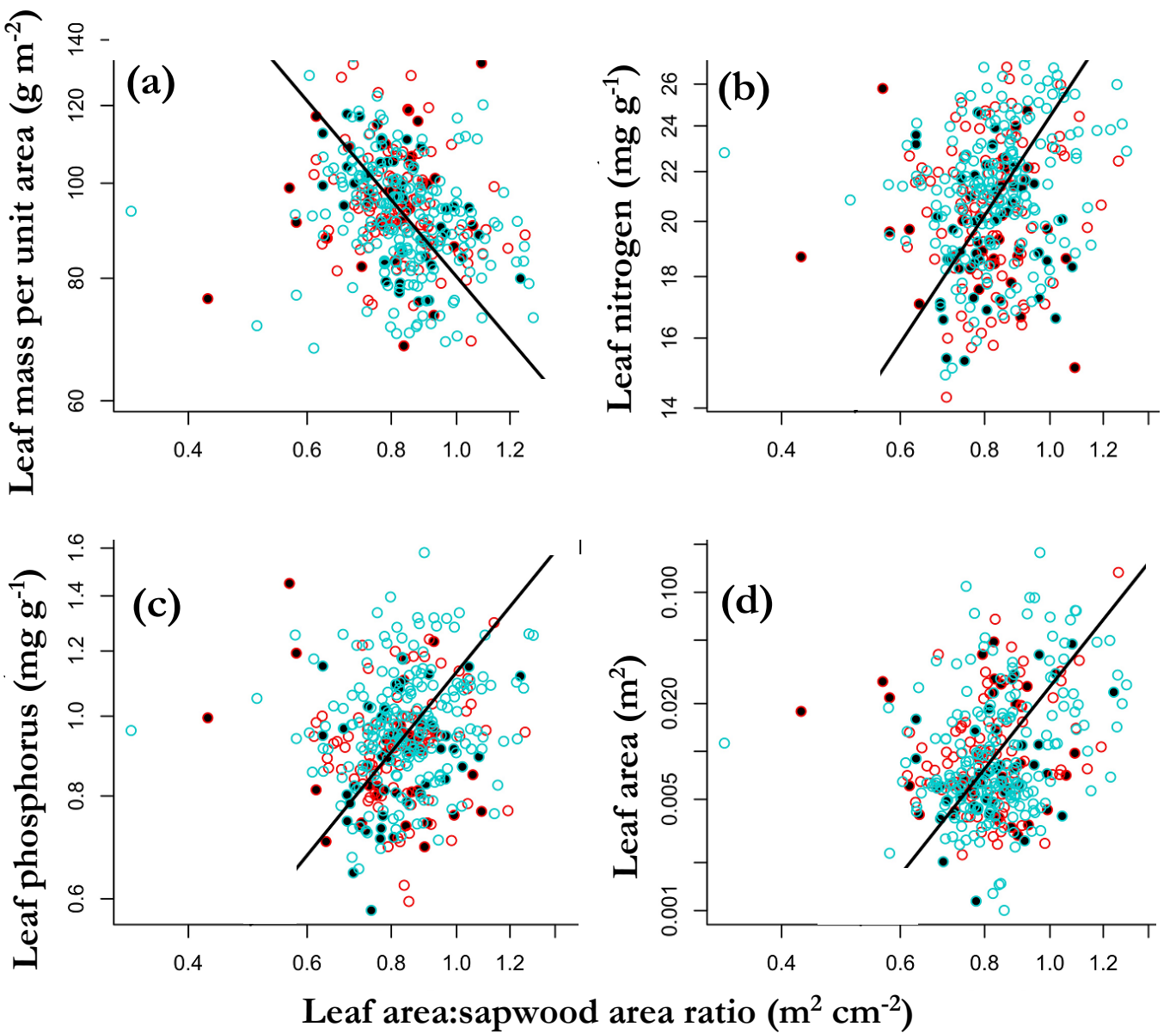

Fig. 5. Standard Major Axis (SMA) regression lines between the derived species components of leaf area/sapwood area ratio ( $\left.\Phi_{\mathrm{LS}}\right)$ and those for mass per unit area $M_{\mathrm{A}}$, foliar [N], foliar [P] and average leaf size for the same species.Red open circles indicate species found on low fertility sites and the blue open circles indicate species found on high fertility sites. Species found on both soil fertility groups are indicated with closed circles (see text for details). Solid lines show the SMA model fit which did not depend on soil fertility.

\subsubsection{Leaf nutrients and other structural traits}

Strong positive correlations $(p \leq 0.001)$ were also observed for $\log _{10}\left(L_{\mathrm{A}}\right)$ with $\log _{10}[\mathrm{~N}]$ and $\log _{10}[\mathrm{P}]$ as well as between $\log _{10}[\mathrm{Ca}]$ and $S$. Interestingly, both the slope and intercept of these relationships are dependent on the soil fertility with which a species is associated (Supplementary Information Table S2B). Species found on low fertility soils tend to have a higher $L_{\mathrm{A}}$ at any given foliar [N] and/or [P].

For the $[\mathrm{Ca}] \leftrightarrow S$ pairing the negative slope is also large $(-8.3)$, though in this case with no soil fertility effect detected. Though not shown in Fig. 6, also of note is the positive $[C] \leftrightarrow S$ relationship $(p \leq 0.001)$ with species with a low seed mass also tending to have a low foliar carbon content.

\subsection{Common Principal Component modelling (taxonomic components)}

Results from the CPC modelling are shown in Table 2, with the full model output, details of the rationale for eigenvector inclusion and assessments of the overall model fit given in the Supplementary Information Tables S3, S4 and S5 and their accompanying captions. The five eigenvectors selected are listed in Table 2 in order of their importance, as derived from the characteristic roots (eigenvectors, $\lambda$ ). These results can be interpreted as in the case of an ordinary principal components analysis, the difference here being that the relative weightings $(\lambda)$ have been allowed to differ for species on high vs. low fertility soils.

The first eigenvector, $U_{1}$, had somewhat higher $\lambda$ for high vs. low fertility associated species (accounting for 0.24 and 0.27 of the dataset variance respectively) and with high positive coefficients for all three foliar cations and to a lesser 
Table 2. Common principal component analysis of derived genetic effects for species associated with low and high fertility soils. Values in brackets represent standard errors for each component. Coefficients given in bold are either those whose absolute values are 0.50 or more, or 0.30 or more with a standard error of less than $0.1 . M_{\mathrm{A}}=$ leaf mass per unit area; elemental concentrations are on a dry weight basis, $L_{\mathrm{A}}=$ leaf area; $\Phi_{\mathrm{LS}}=$ leaf area:sapwood area ratio, $\rho_{\mathrm{x}}=$ branch xylem density, $\oslash=$ diffusion limitation index (see Eq. 1 ), $S=$ seed mass, $H_{\text {max }}=$ species maximum height.

\begin{tabular}{|c|c|c|c|c|c|}
\hline \multirow{2}{*}{ Variable } & \multicolumn{5}{|c|}{ Component } \\
\hline & $U_{1}$ & $U_{2}$ & $U_{3}$ & $U_{4}$ & $U_{5}$ \\
\hline $\log \left(M_{\mathrm{A}}\right)$ & $-0.22(0.05)$ & $-0.23(0.06)$ & $0.44(0.07)$ & $-0.22(0.11)$ & $0.35(0.09)$ \\
\hline [C] & $-0.35(0.05)$ & $0.24(0.07)$ & $0.01(0.07)$ & $0.06(0.12)$ & $0.34(0.09)$ \\
\hline $\log [\mathrm{N}]$ & $0.15(0.10)$ & $0.53(0.04)$ & $-0.02(0.09)$ & $0.22(0.09)$ & $-0.03(0.08)$ \\
\hline $\log [\mathrm{P}]$ & $0.25(0.08)$ & $0.45(0.05)$ & $0.12(0.09)$ & $0.31(0.05)$ & $0.08(0.06)$ \\
\hline $\log [\mathrm{Ca}]$ & $0.42(0.03)$ & $-0.13(0.08)$ & $0.15(0.09)$ & $-0.31(0.06)$ & $0.00(0.08)$ \\
\hline $\log [\mathrm{K}]$ & $0.48(0.02)$ & $-0.01(0.09)$ & $0.00(0.08)$ & $0.16(0.09)$ & $0.05(0.11)$ \\
\hline $\log [\mathrm{Mg}]$ & $0.49(0.04)$ & $-0.21(0.09)$ & $0.07(0.06)$ & $0.06(0.07)$ & $0.19(0.07)$ \\
\hline $\log \left(L_{\mathrm{A}}\right)$ & $-0.01(0.09)$ & $0.48(0.05)$ & $0.25(0.13)$ & $-0.35(0.16)$ & $-0.16(0.10)$ \\
\hline $\log \left(\Phi_{\mathrm{LS}}\right)$ & $-0.01(0.07)$ & $0.29(0.06)$ & $-0.44(0.11)$ & $-0.53(0.16)$ & $0.18(0.11)$ \\
\hline$\rho_{\mathrm{X}}$ & $-0.14(0.03)$ & $-0.03(0.05)$ & $-0.22(0.10)$ & $0.12(0.21)$ & $0.26(0.11)$ \\
\hline$\varnothing$ & $0.10(0.04)$ & $0.14(0.05)$ & $0.39(0.09)$ & $-0.10(0.13)$ & $0.60(0.08)$ \\
\hline $\log (S)$ & $-0.23(0.03)$ & $0.01(0.06)$ & $0.19(0.10)$ & $0.48(0.10)$ & $0.59(0.08)$ \\
\hline$H_{\max }$ & $-0.10(0.04)$ & $0.07(0.06)$ & $0.53(0.10)$ & $-0.13(0.22)$ & $-0.47(0.09)$ \\
\hline \multicolumn{6}{|l|}{ Characteristic roots } \\
\hline$\lambda_{\text {low }, \mathrm{j}}$ & $1876(259)$ & $1472(203)$ & 641(89) & 717 (99) & 698 ( 96) \\
\hline$\lambda_{\text {high }, \mathrm{j}}$ & $2341(237)$ & $1641(166)$ & 898 (91) & $564(57)$ & $318(32)$ \\
\hline
\end{tabular}

Table 3. Bivariate relationships for the derived environmental component of the observed plant traits. Values above the diagonal represent the slope of the relationship (y axis as columns labels, $\mathrm{x}$ axis as row labels). Values below the diagonal represent the correlation coefficient. Values significant at $P<0.05$ are given in bold. NS $=$ no slope estimated as the relationship was not significant. For units and symbols, see Table 1 .

\begin{tabular}{|c|c|c|c|c|c|c|c|c|c|c|c|c|}
\hline Variable & $\log \left(M_{\mathrm{A}}\right)$ & [C] & $\log [\mathrm{N}]$ & $\log [\mathrm{P}]$ & $\log [\mathrm{Ca}]$ & $\log [\mathrm{K}]$ & $\log [\mathrm{Mg}]$ & $\log \left(L_{\mathrm{A}}\right)$ & $\log \left(\ell_{\mathrm{A}}\right)$ & $\log \left(\Phi_{\mathrm{LS}}\right)$ & $\rho_{\mathrm{X}}$ & $\oslash$ \\
\hline $\log (M$ & - & 0.31 & -1.06 & NS & -4.97 & NS & -1.32 & NS & NS & -3.49 & NS & 0.57 \\
\hline [C] & 0.63 & - & -3.38 & NS & -15.86 & NS & -4.22 & NS & NS & NS & 4.10 & 1.82 \\
\hline $\log [\mathrm{N}]$ & -0.52 & -0.30 & - & 2.69 & 4.68 & NS & 1.25 & NS & NS & 3.06 & NS & NS \\
\hline $\log [\mathrm{P}]$ & -0.04 & -0.09 & 0.48 & - & 1.74 & 1.53 & NS & NS & NS & NS & -0.45 & 0.20 \\
\hline $\log [\mathrm{Ca}]$ & -0.28 & -0.54 & 0.28 & 0.50 & - & 0.88 & 0.27 & NS & NS & NS & -0.26 & NS \\
\hline $\log [\mathrm{K}]$ & -0.01 & -0.13 & 0.23 & 0.74 & 0.49 & - & NS & S & NS & NS & $-\mathbf{0 . 3 0}$ & 0.13 \\
\hline $\log [\mathrm{Mg}$ & -0.54 & -0.72 & 0.28 & & 0.50 & 0.05 & - & NS & NS & NS & NS & NS \\
\hline $\log \left(L_{\mathrm{A}}\right)$ & 0.08 & -0.06 & -0.09 & -0.03 & 0.11 & 0.21 & 0.07 & - & 0.85 & NS & NS & NS \\
\hline $\log \left(\ell_{\mathrm{A}}\right)$ & 0.07 & -0.20 & -0.16 & -0.11 & 0.09 & 0.20 & 0.15 & 0.90 & - & NS & -0.79 & -0.35 \\
\hline $\log \left(\Phi_{L S}\right.$ & -0.29 & -0.25 & 0.36 & -0.07 & -0.02 & -0.21 & 0.10 & 0.07 & 0.08 & - & NS & NS \\
\hline$\rho_{\mathrm{X}}$ & 0.08 & 0.27 & -0.22 & -0.64 & -0.46 & -0.82 & -0.06 & -0.25 & -0.31 & 0.17 & - & NS \\
\hline$\oslash$ & 0.32 & 0.27 & 0.24 & 0.49 & 0.25 & 0.31 & -0.22 & -0.14 & -0.28 & -0.09 & -0.18 & . \\
\hline
\end{tabular}

extent foliar [P], and negative coefficients for foliar [C] with smaller but still significant coefficients for $M_{\mathrm{A}}$ and $S$. In terms of cations, carbon and $M_{\mathrm{A}}$, this first component seems similar to that first described by Poorter and de Jong (1999) and thus we dub it the Poorter-De Jong (PDJ) dimension, Д PDJ. $_{\text {. }}$

The second component, $U_{2}$, accounts for an additional 0.18 and 0.19 of the dataset variances for low and high fertility species respectively, and is characterised by high positive coefficients for foliar $[\mathrm{N}]$ and $[\mathrm{P}]$ as well as $L_{\mathrm{A}}$ and, to a lesser extent, $\Phi_{\mathrm{LS}}$. Also notable are modestly negative coefficients for $M_{\mathrm{A}}$ and foliar [Mg]. In terms of [N], [P] and $M_{\mathrm{A}}, U_{2}$, seems to reflect some components of what is considered the classic leaf economic spectrum (Reich et al., 1997; Wright et al., 2004). We thus label this the Reich-Wright dimension, $\lambda_{\mathrm{RW}}$, of tropical tree functional trait coordination.

Although $H_{\max }$ would seem to have little influence on either $Д_{\mathrm{PDJ}}$ or $Д_{\mathrm{RW}}$ it emerges as the dominant term for $U_{3}$ 

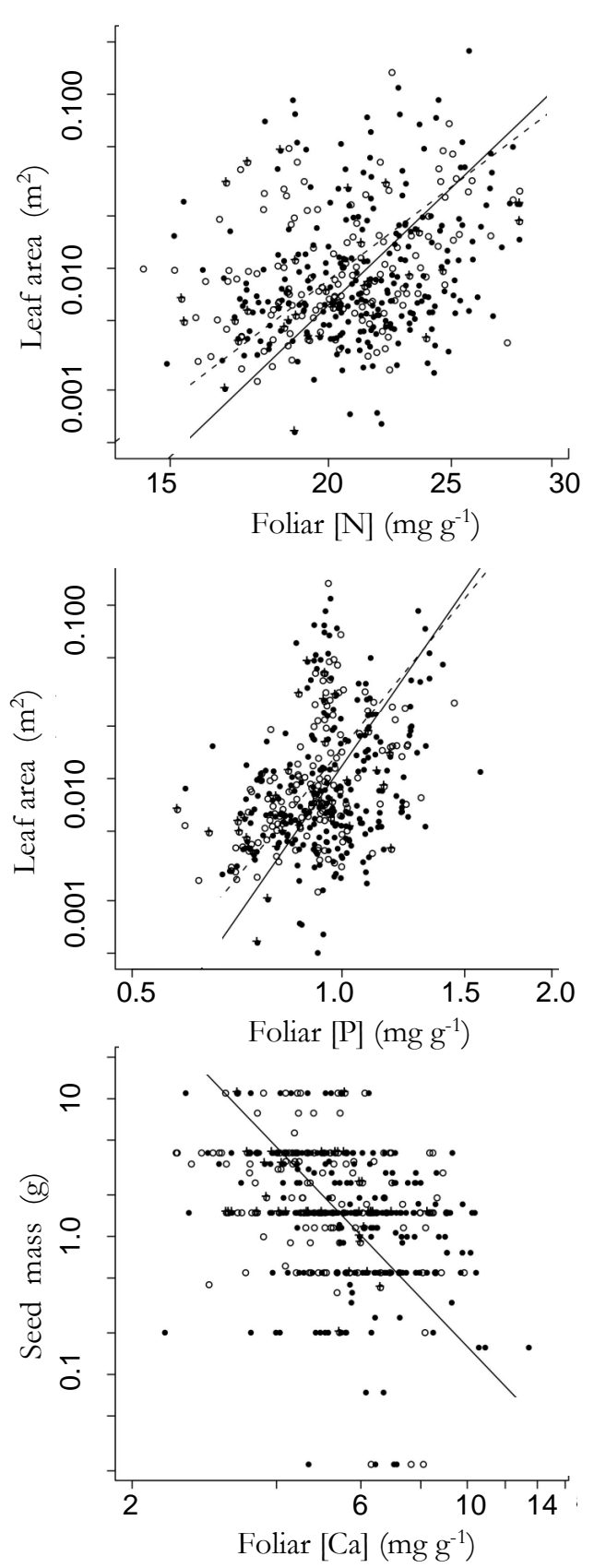

Fig. 6. Standard Major Axis (SMA) regression lines between derived taxonomic components of foliar $[\mathrm{N}]$ and foliar $[\mathrm{P}]$ and leaf mass per unit area $\left(L_{\mathrm{A}}\right)$ for the top two panels and between species estimated foliar $[\mathrm{Ca}]$ associated average seed mass $(S)$ for the associated genus (bottom panel). Open circles indicate species found on low fertility sites and the closed circles indicate species found on high fertility sites. Species found on both soil fertility groups are designated by a "+" (see text for details). For the top two panels, solid lines show the SMA fit for low fertility soil species which are significantly different to the dashed lines for high fertility soil species. For the bottom panel the solid lines shows the SMA model fit which did not depend on soil fertility. along with $M_{\mathrm{A}}$ and, of opposite sign, $\Phi_{\mathrm{LS}}$. Also of note here is the relatively high value for the coefficient of the diffusion limitation index, $\oslash$ which is positively associated with both $H_{\max }$ and $M_{\mathrm{A}}$. Interestingly, for this component $L_{\mathrm{A}}$ varies in the opposite direction to $\Phi_{\mathrm{LS}}$ (albeit with a large standard error) suggesting that there is a tendency towards considerably fewer but also significantly larger leaves in taller statured species. There also being a modest but significant negative contribution of $\rho_{\mathrm{x}}$ to this dimension. We consider $U_{3}$, which on its own accounts for 0.08 and 0.10 of the variation in the dataset respectively, to contain several features similar to those described by Falster and Westoby (2005) for climax tropical forest in Australia, and it is thus denoted as Д $_{\mathrm{FW}}$.

The fourth component axis is dominated by $S$ and $\Phi_{\mathrm{LS}}$ with these coefficients of different sign. Associated with the higher $S$ are also lower [Ca] but higher foliar $[\mathrm{P}]$ and $L_{\mathrm{A}}$. With lower values for their coefficients and higher standard errors, also being of different sign, are the $M_{\mathrm{A}}$ and $[\mathrm{N}]$ terms. As mentioned in the Discussion, $U_{4}$ (accounting for 0.09 and 0.07 of the population variance for low and high fertility species respectively) seems to be dominated by the presence of large seeded members of the Leguminaceae whose importance in the phytogeography of Amazon forest has already been recognised by ter Steege et al. (2006). We therefore denote this dimension as $Д_{T S}$.

The last eigenvector included in our analysis, $U_{5}$, differs from the others in having a substantially greater importance for low fertility versus high fertility species (accounting for 0.09 and 0.04 of the population variances respectively). This component is characterised by $H_{\max }$ and $M_{\mathrm{A}}$ having opposite signs (in contrast to $Д_{\mathrm{FW}}$ ) and with higher $S$ and $\oslash$ also being associated with a lower $H_{\max }$; this also being along with a less substantial but significant coefficient for $\rho_{\mathrm{x}}$. Also of influence in characterising $U_{5}$ are greater foliar [C] associated with the higher $M_{\mathrm{A}}$ and $\oslash$. Although, $U_{5}$ presents some trait combinations as reported previously in the literature, this component, mostly related with species found at low fertility soils, does not seem to have been recognised before. It is thus here denoted as $Д_{\mathrm{PFL}}$.

Overall the five eigenvectors selected, all of which we believe to be physiologically relevant (see Supplementary Information), accounted for 0.68 of the total variance for both low and high fertility soil species.

The first three axes species scores (normalised to \pm 100 ) are plotted against each other in Supplementary Information Fig. S1. This shows the required lack of any systematic correlations between the species scores as expected for the output from any good fit of a principle components model. Clearly a wide range of combinations of these three trait dimensions can occur. Figure 8a also shows that it is (generally speaking) only species typically associated with high fertility soils that have high scores for both $Д_{\mathrm{PDJ}}$ and $\mathrm{Д}_{\mathrm{RW}}$.

Figure 7 shows the major components of the three major $\mathrm{CPCs}$ and their overlap of traits in diagrammatic form. This 


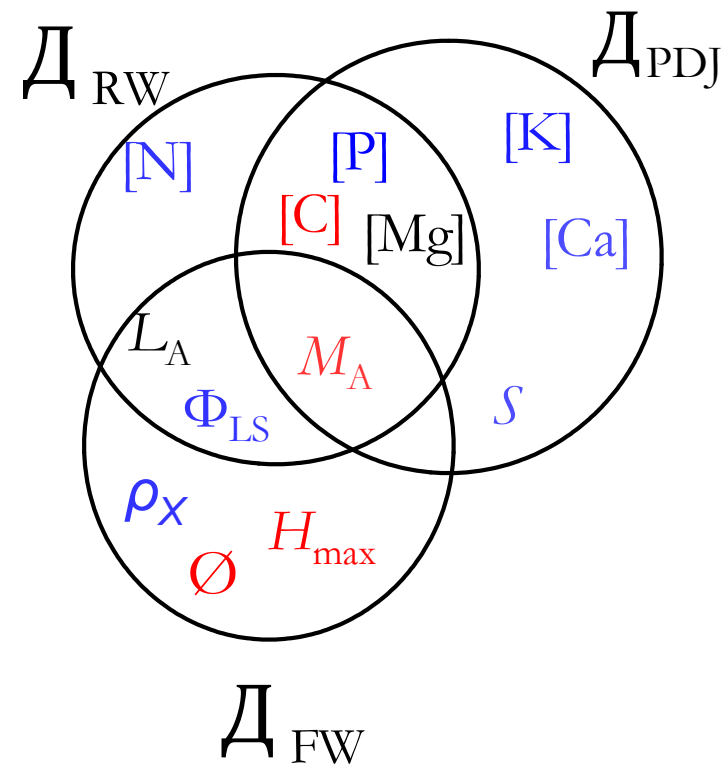

Fig. 7. Euler diagram showing overlaps between the first three dimensions for the individual measured traits (where significant): blue; positive relationship with dimension, red; negative relationship with dimension, black; of different sign depending on the dimension. Abbreviations are as in Table 5, with the three trait dimensions as defined in Sect. 3.5

illustrates that many traits seem to be "shared", especially $M_{\mathrm{A}}$ which is an important factor for all three of $Д_{\mathrm{PDJ}}, Д_{\mathrm{RW}}$

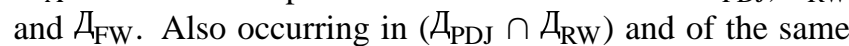
sign is $[\mathrm{C}]$, but with $[\mathrm{P}]$ and $[\mathrm{Mg}]$ varying in opposite directions with respect to $M_{\mathrm{A}}$ for these two trait dimensions. Intersecting $\lambda_{\mathrm{RW}}$ and $\lambda_{\mathrm{FW}}$ and in the same direction relative to $M_{\mathrm{A}}$ is $\Phi_{\mathrm{LS}}$. Although with a high estimated standard error as part of $Д_{\mathrm{FW}}$, we have also included $L_{\mathrm{A}}$ in $\left(Д_{\mathrm{RW}} \cap \mathrm{Д}_{\mathrm{FW}}\right)$, this also showing that it varies in the opposite direction relative to $M_{\mathrm{A}}$ and $\Phi_{\mathrm{LS}}$ for $Д_{\mathrm{RW}} c f$. $Д_{\mathrm{FW}}$.

\subsection{Bivariate relationships: environmental components}

Considering data from both low and high fertility sites together, Table 3 lists correlations and SMA slopes for the environmental effects with this information provided in more detail (including confidence intervals) in the Supplementary Information (Table S2A). As for Table 1, the SMA slopes reflect the relationship $y \leftrightarrow x$, with the $x$ as the column headers and the $y$ being the row labels. For the structural traits, the most significant relationships are all negative and appear between $\rho_{\mathrm{x}}$ and $\log _{10}[\mathrm{P}], \log _{10}[\mathrm{Ca}], \log _{10}[\mathrm{~K}]$ and, to a lesser extent $\log _{10}\left(\ell_{\mathrm{A}}\right)$. The slopes observed $(-0.26$ to -0.41$)$ are, however, much less than for the associated slopes for the taxonomic components as listed in Table $1(-0.37$ to -0.72$)$.
Table 4. Summary of the Principal Components Analysis of the correlation matrix for the derived environmental/soil effects on observed structural and physiological traits. Coefficients given in bold are those whose values are 0.3 or more. $M_{\mathrm{A}}=$ leaf mass per unit area; elemental concentrations are on a dry weight basis, $\mathrm{L}_{\mathrm{A}}=$ leaf area; $\Phi_{\mathrm{LS}}=$ leaf area: sapwood area ratio, $\rho_{\mathrm{X}}=$ branch xylem density, $\oslash=$ diffusion limitation index (see Eq. 1)

\begin{tabular}{l|rr}
\hline Variable & \multicolumn{2}{|c}{ Component } \\
& $\Psi_{1}$ & $\Psi_{2}$ \\
\hline $\log \left(M_{\mathrm{A}}\right)$ & -0.196 & $-\mathbf{0 . 4 4 3}$ \\
{$[\mathrm{C}]$} & $-\mathbf{0 . 3 0 0}$ & $-\mathbf{0 . 4 1 2}$ \\
$\log [\mathrm{N}]$ & $\mathbf{0 . 3 2 0}$ & 0.111 \\
$\log [\mathrm{P}]$ & $\mathbf{0 . 4 0 6}$ & -0.276 \\
$\log \left[C_{\mathrm{A}}\right]$ & $\mathbf{0 . 4 5 3}$ & 0.099 \\
$\log [\mathrm{K}]$ & $\mathbf{0 . 3 9 2}$ & -0.300 \\
$\log \left[M_{\mathrm{g}}\right]$ & 0.245 & $\mathbf{0 . 4 1 6}$ \\
$\log \left(L_{\mathrm{A}}\right)$ & 0.087 & -0.009 \\
$\log \left(\Phi_{\mathrm{LS}}\right)$ & 0.025 & 0.271 \\
$\rho_{\mathrm{X}}$ & $-\mathbf{0 . 3 8 3}$ & 0.287 \\
$\oslash$ & 0.174 & $-\mathbf{0 . 3 4 0}$ \\
\hline Eigenvalue & 6.23 & 2.54 \\
\hline Proportion of variance explained & 0.33 & 0.25 \\
\hline
\end{tabular}

\subsection{Principal component analysis of environmental effects}

Given the correlations between the environmental effects for $\rho_{\mathrm{x}}$ and several foliar nutrients (Table 3; Fig. 8), it was of additional interest to see if coordinated structural/leaf biochemical responses to the environment exist for Amazon forest. We therefore undertook a PCA analysis of the full plot effects correlation matrix (excluding $H_{\max }$ and $S$ both of which were considered to be environmentally invariant for any given species) with the results shown in Table 4. This shows that 0.33 of the total variation in the 11 traits examined could be explained by the first PCA axis $\left(\psi_{1}\right)$ with $\rho_{\mathrm{x}}$ an important contributor and this also relating positively to foliar $[C]$ and $M_{\mathrm{A}}$, but negatively with all foliar nutrients examined and also with $\oslash$. The second axis of the PCA on the plot effects correlation matrix $\left(\psi_{2}\right)$ is also significant, accounting for 0.25 of the variance, with substantial negative weightings for $M_{\mathrm{A}}$, foliar $[\mathrm{C}]$ and $\oslash$ (and to a lesser extent foliar [P]) being balanced by positive weightings for foliar $[\mathrm{Mg}]$ in particular, but also with contributions from $\Phi_{\mathrm{LS}}$ and $\rho_{\mathrm{x}}$.

\subsection{Relationship between plot effect PCAs and soil/climate}

The most significant relationships between the PCA site axis scores of Table 4, and previously calculated soil and climate characteristics of the same sites are shown in Fig. 9. First, the top panel of Fig. 9 shows $\psi_{1}$ as a function of the first soil PCA axis of Fyllas et al. (2009), the latter considered a strong 
Table 5. Kendall's partial correlation coefficient, $\tau_{\mathrm{P}}$, for the environmental contribution (plot effect estimate) of each foliar property (controlling for the effects of the other environmental predictors) with their significance estimated as detailed in Maghsoodloo and Laszlo Pallos (1981). Bold values indicate a very strong correlation $(p<0.001)$ and italics indicate significant correlations at $p<0.01$; see text for details. $M_{\mathrm{A}}=$ leaf mass per unit area; elemental concentrations are on a dry weight basis, $L_{\mathrm{A}}=$ leaf area; $\ell_{\mathrm{A}}=$ leaflet area, $\Phi_{\mathrm{LS}}=$ leaf area/sapwood area ratio, $\rho_{\mathrm{X}}=$ branch xylem density, $\oslash=$ diffusion limitation index (see Eq. 1) and $\psi_{1}$ and $\psi_{2}$ are the first two principal components of the PCA analysis on the environmental effects correlation matrix (See Table 4).

\begin{tabular}{|c|c|c|c|c|c|c|c|c|c|c|c|c|c|c|}
\hline & $\mathrm{M}_{\mathrm{A}}$ & {$[\mathrm{C}]$} & {$[\mathrm{N}]$} & {$[\mathrm{P}]$} & {$[\mathrm{Ca}]$} & {$[\mathrm{K}]$} & {$[\mathrm{Mg}]$} & $\mathrm{L}_{\mathrm{A}}$ & $\ell_{\mathrm{a}}$ & $\log \left(\Phi_{\mathrm{LS}}\right)$ & $\rho_{\mathrm{X}}$ & $\oslash$ & $Y_{1}$ & $\varphi_{2}$ \\
\hline Soil fertility PCA axis, $\phi_{\mathrm{F}}$ & -0.20 & -0.23 & 0.20 & 0.48 & 0.48 & 0.33 & 0.22 & -0.09 & -0.07 & -0.04 & -0.32 & 0.20 & 0.56 & 0.00 \\
\hline Soil texture PCA axis, $\phi_{\mathrm{T}}$ & 0.05 & 0.10 & 0.12 & 0.04 & -0.27 & -0.17 & -0.18 & -0.03 & 0.02 & 0.05 & 0.19 & 0.02 & -0.22 & -0.07 \\
\hline Mean annual temperature, $\mathrm{T}_{\mathrm{a}}$ & 0.11 & 0.051 & -0.38 & -0.26 & -0.08 & -0.41 & 0.03 & -0.08 & -0.04 & 0.07 & 0.35 & -0.13 & -0.23 & 0.21 \\
\hline Mean annual precipitation, $\mathrm{P}_{\mathrm{a}}$ & 0.33 & 0.30 & -0.18 & 0.17 & -0.01 & 0.11 & -0.31 & -0.01 & -0.01 & 0.17 & -0.12 & 0.24 & -0.07 & -0.44 \\
\hline Mean annual radiation, $\mathrm{Q}_{\mathrm{a}}$ & -0.06 & 0.15 & 0.02 & 0.12 & -0.14 & 0.08 & 0.00 & -0.11 & -0.10 & 0.08 & 0.02 & 0.12 & -0.04 & -0.11 \\
\hline
\end{tabular}
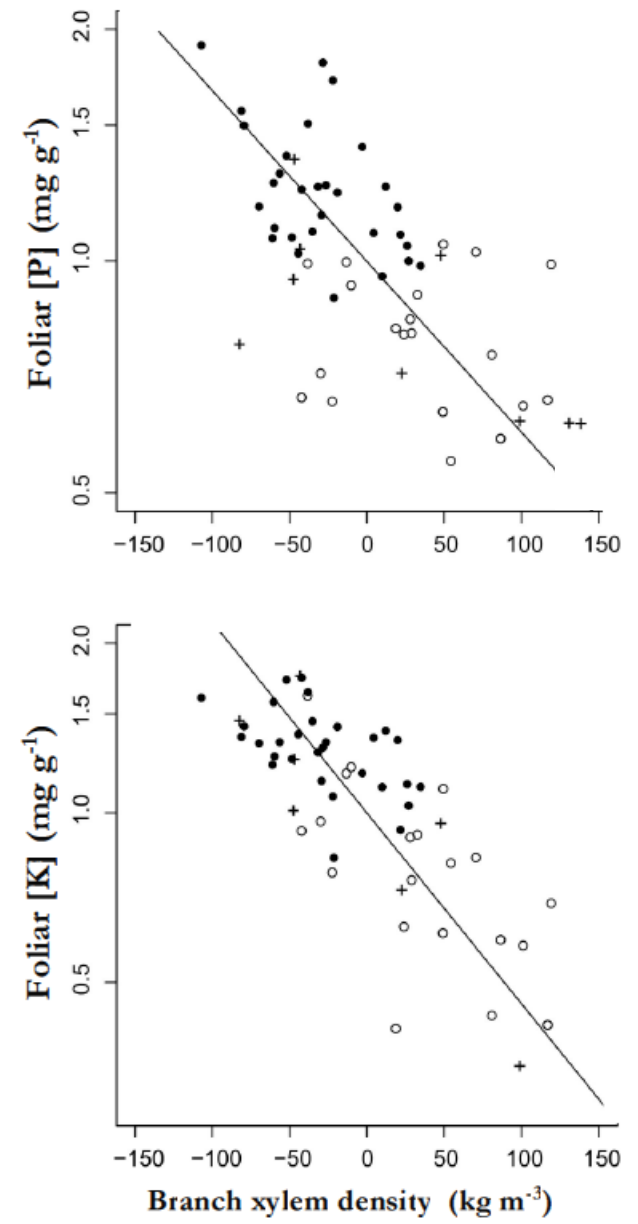

Fig. 8. Standard Major Axis (SMA) regression lines between the derived environmental components of branch xylem density $\left(\rho_{\mathrm{X}}\right)$ and foliar $[\mathrm{P}]$ and foliar $[\mathrm{K}]$. Open circles indicate species found on low fertility sites and the closed circles indicate species found on high fertility sites. Species found on both soil fertility groups are designated by a "+" (see text for details). Solid lines show the SMA model fits. integrated measure of soil fertility and denoted $\phi_{\mathrm{F}}$. The strong relationship observed suggests an integrated response of Amazon tropical forest trees to soil fertility, with most nutrients increasing, and with foliar $[\mathrm{C}]$ and $\rho_{\mathrm{x}}$ decreasing as $\phi_{\mathrm{F}}$ increases. Interestingly, the Kendall's $\tau$ for this plot of $\Psi_{1}$ versus $\phi_{\mathrm{F}}$ of 0.63 is greater than for any of the original variables examined by Fyllas et al. (2009), the highest of which was 0.56 for foliar [P]. Comparison with Fyllas et al. (2009) also shows that the $\Psi_{2}$ contains significant weightings of leaflevel variables that, individually, were all strongly correlated with mean annual precipitation $\left(P_{\mathrm{A}}\right)$ viz. positive correlations with foliar [C] and $M_{\mathrm{A}}$ and a negative correlation with foliar [Mg]. It is therefore not surprising, as is shown in the second panel of Fig. 9, that $\psi_{2}$ and $P_{\mathrm{A}}$ also show strong association, but with examination of Table 4 also suggesting that for any given species, both $\Phi_{\mathrm{LS}}$ and $\rho_{\mathrm{W}}$ also decline with increasing precipitation and, somewhat counter intuitively, with $\oslash$ increasing.

Finally, as in Fyllas et al. (2009) we show values for Kendall's partial $\tau$ (denoted $\tau_{\mathrm{p}}$ ) for all traits of interest as well as $\psi_{1}$ and $\psi_{2}$ as functions of $\phi_{\mathrm{F}}, \phi_{\mathrm{T}}, T_{\mathrm{a}}, P_{\mathrm{a}}$ and $Q_{\mathrm{a}}$ in Table 5. Here the calculated value of $\tau_{\mathrm{p}}$ and associated probability giving an indication of the effect of each soil/environmental parameter after accounting for the effect of the other four. Taking into account the potential confounding effects of spatial autocorrelation (Fyllas et al., 2009) we only consider relationships with $p \leq 0.01$ or better. As for the (full) Kendall's $\tau$ shown in Fig. 9, Table 5 suggests the $\phi$ to be superior predictors than the individual variables, the only exception being $T_{\mathrm{a}}$. In that case, $[\mathrm{N}],[\mathrm{K}]$ and $\rho_{\mathrm{w}}$ all show relationships not present when regressing the plot effect PCs as dependent variables.

\section{Discussion}

Some of the data used here have been presented previously (Fyllas et al., 2009; Patiño et al., 2009), with the current analysis integrating those datasets with structural traits introduced as part of this study (viz. $L_{\mathrm{A}}, \ell_{\mathrm{A}}, \Phi_{\mathrm{LS}}, S$ and $H_{\max }$ ) 

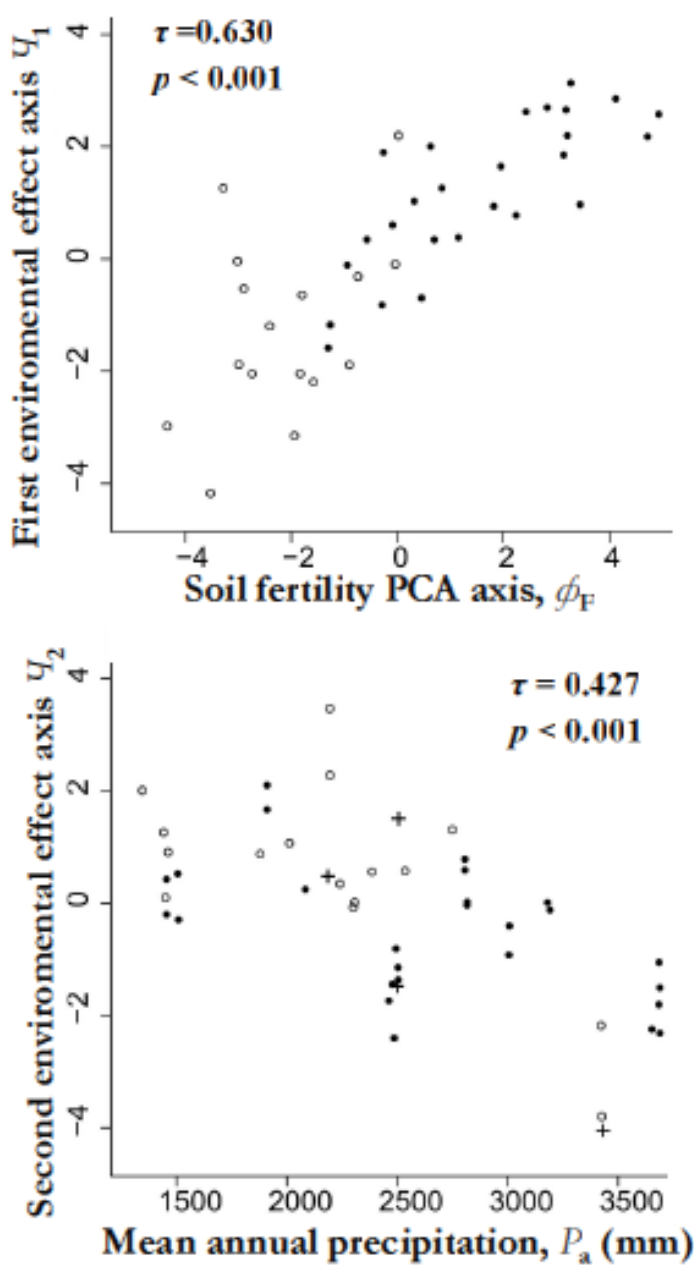

Fig. 9. Relationship between derived environmental effect principal components (Table 5) and soil/environmental parameters for various plots across the Amazon. Top panel, first principal component of the environmental effects versus the first principal component of the PCA of soil chemical and physical characteristics as derived by Fyllas et al. (2009) on the basis of data provided by Quesada et al. (2010). Second panel, second principal component of the environmental effects PCA versus mean annual precipitation. Open circles indicate low fertility sites and the closed circles indicate high fertility sites as defined by Fyllas et al. (2009).

as well as with foliar ${ }^{13} \mathrm{C} /{ }^{12} \mathrm{C}$ ratios as reinterpreted through the diffusional limitation index, $\oslash$, as defined by Eq. (1). We first consider the bivariate relationships between the structural components introduced as part of this study as well as relationships between these structural traits and the others already presented (Fyllas et al., 2009; Patiño et al., 2009), this then being extended to a consideration of how variations in these traits coordinate in response to differences in species and/or environment. Here we emphasise that, as estimated within the study, our "environmental effects" reflect modulation of taxon specific trait values by soils and/or cli- mate. To this extent they reflect a systematic component of intra-species variability, i.e. that predictable from where a particular species is growing, as opposed to a more random within population component, such as might be expected when comparing the same species growing nearby under the same edaphic and climatic conditions. This portion, along with experimental error is theoretically included in the residual component of the analysis (i.e., that not accounted for by the fitted model itself ) which, as shown in Figure 2, can sometimes be substantial. The extent to which this component of trait variation relates to within plot variability in microclimate or soil characteristics (rather than intrinsic withinspecies differences or sampling/measurement error) remains to be established.

\subsection{Bivariate relationships for the taxonomic component of trait variation}

\subsubsection{Maximum tree height, branch xylem density and leaf mass per unit area}

These three structural traits have often been associated with each other with significant positive $\rho_{\mathrm{X}} \leftrightarrow M_{\mathrm{A}}$ correlations such as for our taxonomic component in Fig. 4 also reported by Bucci et al. (2004), Ishida et al. (2008) and Meinzer et al. (2008). Those studies interpreted this relationship in terms of higher density wood species having lower hydraulic conductances leading to a requirement for more robust leaves capable of sustaining more severe soil water deficits. This notion is supported by more negative osmotic potentials being reported for the leaves of higher $M_{\mathrm{A}}$ and $\rho_{\mathrm{x}}$ species (Bucci et al., 2004; Ishida et al., 2008; Meinzer et al., 2008). On the other hand, it is also the case that $M_{\mathrm{A}}$ tends to increase with actual or potential (maximum) tree height (Falster and Westoby, 2005; Kenzo et al., 2008; Lloyd et al., 2010) and that $\rho_{\mathrm{w}}$ and $H_{\max }$ are sometimes negatively correlated (Falster and Westoby, 2005; van Gelder et al., 2006). This then implying that $\rho_{\mathrm{w}}$ and $M_{\mathrm{A}}$ should be negatively (as opposed to positively) correlated as well.

One reason for this apparent contradiction may be that wood density and xylem vessel traits do not necessarily represent the same axis of ecophysiological variation (Preston et al., 2006; Martinéz-Cabrera et al., 2009; Poorter et al., 2010; Baraloto et al., 2010). For example, decreasing wood density associated with increasing foliar $\mathrm{P}$ concentration and lower LMA is also likely associated with decreasing investment in wood physical and chemical defences (Augspurger, 1984; Putz et al., 1983; King, 1986; Chao et al., 2008), including resistance against breakage (Romero and Bolker, 2008). One interpretation of Fig. $4 \mathrm{a}-\mathrm{c}$ is then simply that tropical tree species with traits associated with a higher photosynthetic potential such as a high foliar [P] (Domingues et al., 2010), also tend to invest less towards wood defensive strategies (but see Larjavaara and Muller-Landau, 2010). 
Our observation of significant within-species variation in $\rho_{\mathrm{x}}$ as illustrated in more detail by Patiño et al. (2009) and also observed for $\rho_{\mathrm{w}}$ by Omolodun et al. (1991), Hernández and Restrepo (1995), Gonzalez and Fisher (1998), Weber and Montes (2008) and Sungpalee et al. (2009), shows important intraspecific variation in xylem and/or wood density even within one plot (as also evidenced by the "residual" term for $\rho_{\mathrm{x}}$ in Fig. 2) as well as being systematically affected by soil fertility (Table 5 ). Thus, although we do not dispute that xylem traits and $\rho_{\mathrm{w}} / \rho_{\mathrm{x}}$ may not necessarily be closely or mechanistically linked (as discussed above), studies which simply compare wood density "species values" as measured in one study or studies with values of $\rho_{\mathrm{w}} / \rho_{\mathrm{x}}$ for the same species but gathered from a completely independent source (Russo et al., 2010; Zanne et al., 2010) are effectively comparing bananas with wombats. Thus, also not employing robust regression techniques more applicable to such analyses (McKean et al., 2009) they must under-estimate the actual significance of any relationship, be it functional or not.

So, does the observation of large diameter xylem vessels with a high $K_{\mathrm{S}}$ also being associated with a greater $H_{\max }$ (e.g., Poorter et al., 2010; Zach et al., 2010) mean that the tendency of mature forests species of a greater $H_{\max }$ to also have a lower $\rho_{\mathrm{w}}$ (Falster and Westoby, 2005; van Gelder et al., 2006; Baker et al., 2009; Poorter et al., 2009) is indicative of some sort of functional linkage? Or does it more simply reflect that the fast-growing and light-demanding species characteristic of "dynamic" tropical forests also tend to have a lower $\rho_{\mathrm{w}}$ - this presumably allowing a faster height and diameter growth rate? On the basis of the discussion above, we suggest the latter, also noting that $\rho_{\mathrm{w}}$ is actually generally better correlated with juvenile light-exposure than $H_{\max }$ (van Gelder et al., 2006; Poorter et al., 2009).

The positive relationship between $M_{\mathrm{A}}$ and $H_{\max }$ of Fig. 3a and as also evident in the data of Falster and Westoby (2005) can also be inferred from the positive $M_{\mathrm{A}}$ vs. tree height relationships as reported by Thomas and Bazzaz (1999), Kenzo et al. (2006) and Lloyd et al. (2010). This is also seen within $Д_{\mathrm{FW}}$ in the CPC analysis of Table 3, with the leaves of (potentially) taller trees being thicker (Kenzo et al., 2006; Rozendaal et al., 2006) with a greater mesophyll thickness associated with a higher photosynthetic capacity per unit area (Kenzo et al., 2006). This increase in $M_{\mathrm{A}}$ with tree height being mostly associated with a greater mesophyll thickness should allow for a more efficient use of the higher rates of insolation towards the canopy top through higher photosynthetic capacities per unit leaf area (Rijkers et al., 2000). Along with more negative osmotic potentials, the greater tissue densities associated with a higher $M_{\mathrm{A}}$ and $H_{\max }$ should also help sustain leaves of such taller trees in the face of the more severe water deficits expected for sun exposed leaves higher up in the canopy (Cavaleri et al., 2010; Lloyd et al., 2010).

\subsubsection{Leaf size, nutrients and $\Phi_{L S}$}

Species with intrinsically higher foliar nutrient concentrations also tend to be found on more fertile soils (Fyllas et al., 2009), and so the positive correlation between the taxonomic components of leaf size variation, foliar $[\mathrm{N}]$ and foliar [P] observed here (Fig. 6) is consistent with the observation that Australian tropical forest tree species associated with poorer soils tend to have smaller leaves than those associated with more eutric conditions (Webb, 1968). This was also found to be the case for south-eastern Australian woodland species once precipitation effects were also taken into account (McDonald et al., 2003). Such a relationship has also been observed for pre-montane subtropical forest species in Argentina (Easdale and Healey, 2009) and has been suggested to be a widespread phenomenon (Givnish, 1987) perhaps being explainable by low $\mathrm{N}$ and/or $\mathrm{P}$ leaves typically having lower gas exchange rates than those of a higher fertility status (Domingues et al., 2010); with associated lower latent heat loss rates due to lower stomatal conductances. This would give rise to a greater rate of sensible heat loss being required to avoid over-heating during times of high insolation being achieved through the higher boundary layer conductance of smaller leaf sizes (Yates et al., 2010). Alternatively, and consistent with the general notion of plants growing on less fertile soils having more conservative growth strategies (Westoby et al., 2002), smaller leaves may be favoured on low nutrient soils despite their relatively higher construction costs. This is because they also have shorter expansion times with an associated reduction in herbivory losses during this susceptible phase of foliar development (Moles and Westoby, 2000). If the "heat budget" explanation were to be correct, then an even better correlation with $\ell_{\mathrm{A}}$ would be expected for both foliar $[\mathrm{N}]$ and $[\mathrm{P}]$. But this was not the case (Table 1) with both foliar $[\mathrm{N}]$ and $[\mathrm{P}]$ much more closely correlated with $L_{\mathrm{A}}$. On the other hand, the relationship between leaf size and expansion time does not appear to differ strongly between simple vs. compound leaves (Moles and Westoby, 2000). This suggests that the herbivory hypothesis may be the more correct.

Although not significant across the dataset as a whole, there was a significant negative correlation between $L_{\mathrm{A}}$ and $\rho_{\mathrm{x}}$ for species characteristic of low fertility sites $\left(r^{2}=\right.$ $-0.17, p \leq 0.05$ : Supplementary Information, Table S2B) as has also been reported for Australian tree/shrub species by Pickup et al. (2005) and Wright et al. (2007) and for neotropical forest tree species by Swenson and Enquist (2008), Malhado et al. (2009), Baraloto et al. (2010) and, with a much lower correlation $\left(r^{2}=-0.02\right)$ by Wright et al. (2006). Exactly as to why this should be the case is currently unclear. Earlier arguments have revolved around not only $\rho_{\mathrm{x}}$ and $K_{\mathrm{S}}$ being closely linked, but also with the assumption that variations in $L_{\mathrm{A}}$ should to a large extent reflect variations in $\Phi_{\mathrm{LS}}$ (Wright et al., 2006). But, as discussed in Sect. 4.1.1, wood density and plant hydraulics may not be as closely linked as 
once thought and, although $\Phi_{\mathrm{LS}}$ is indeed correlated with $L_{\mathrm{A}}$ (Fig. 6), our data do not actually show any appreciable correlations between $\Phi_{\mathrm{LS}}$ and $\rho_{\mathrm{x}}$ (Table 1; Supplementary Information, Table S2B). This suggests that for tropical trees at least, this correlation may be more "casual" than mechanistic. Indeed, both for the dataset as a whole and for the individual fertility groupings, $\rho_{\mathrm{x}}$ was better (negatively) correlated with $\ell_{\mathrm{A}}$ than $L_{\mathrm{A}}$ (Table 1, Supplementary Information, Table S2B). Given that compound leaves are generally associated with faster diameter increment species (Givnish, 1978; Malhado et al., 2010) as is a generally lower $\rho_{\mathrm{x}}$ (Keeling et al., 2008) this then suggests that the negative correlation between laminar size and wood density may just reflect both traits being associated with faster growth rates. As well as tending to have lower $\rho_{\mathrm{w}}$ (Sect. 4.1.2) such species also tend to exhibit less branching than more shade tolerant species (Poorter et al., 2006; Poorter and Rozendaal, 2006; Takahashi and Mikami, 2008). Presumably (along with wider spacings) this allows for larger leafed upper-canopy species to have greater rates of direct light interception (Falster and Westoby, 2003).

Increasing $M_{\mathrm{A}}$ with decreasing $\Phi_{\mathrm{LS}}$ as shown in Fig. 5 does not seem to have been detected in other studies with tropical tree species (Meinzer et al., 2008; Zhang and Cao, 2009). Although it is notable that working with a range of emergent or upper-canopy dipterocarp species, Zhang and Chao (2009) did find a significant negative relationship between $\Phi_{L S}$ and leaf thickness, the latter being associated with variations in $M_{\mathrm{A}}$ with tree height for dipterocarp species (Kenzo et al., 2006). Sampling across a range of sites in south-eastern Australia, Pickup et al. (2005) also found a negative relationship between $M_{\mathrm{A}}$ with $\Phi_{\mathrm{LS}}$ but this relationship was, overall, not significant for species sampled within individual sites. Our own data suggest a stronger linkage of $M_{\mathrm{A}}$ with $\Phi_{\mathrm{LS}}$ than either $L_{\mathrm{A}}$ or (indeed even of different sign) $\ell_{\mathrm{A}}$. This suggests (as is discussed further in Sect. 4.2) that this linkage may be mostly related to plant hydraulics considerations. The positive relationship between $\ell_{\mathrm{A}}$ and $M_{\mathrm{A}}$ may reflect constraints on the range of possible combinations of leaf(let) size and $M_{\mathrm{A}}$, with larger laminar areas necessarily requiring a greater (minimum) $M_{\mathrm{A}}$ due to structural constraints (Grubb, 1998).

Not surprisingly, $L_{\mathrm{A}}$ and $\Phi_{\mathrm{LS}}$ were related, but with a scaling coefficient of only 0.17 , meaning that a greater leaf size was to a substantial degree compensated for by reduced numbers of leaves per unit sapwood area $A_{\mathrm{S}}$. This points to $\Phi_{\mathrm{LS}}$ being a relatively invariate trait as has also been reported by others (e.g., Westoby and Wright, 2003). Of note, $\Phi_{\text {LS }}$ was also correlated with foliar [P] and [N] (Fig. 5), although this correlation was weaker for $L_{\mathrm{A}}$, especially in the case of foliar phosphorus. But for both nitrogen and phosphorus, the slope was still positive and close to 1.0. Thus tropical tree species with larger leaves tend to have not only higher $[\mathrm{P}]$ and $[\mathrm{N}]$ (and by implication higher gas exchange rates) but also a higher $\Phi_{\mathrm{LS}}$. As there is little evidence of greater diffusional limitations on gas exchange for such leaves (as shown by the lack of any significant relationship between $\Phi_{\mathrm{LS}}$, [N], [P] or $L_{\mathrm{A}}$ with $\oslash$ ), this implies that accompanying a higher $\Phi_{\mathrm{LS}}$ are also increased $K_{\mathrm{S}}$ as also observed by Vander Willigen et al. (2000) for subtropical trees and also by Cavender-Bares and Holbrook (2001) for a range of Quercus species.

\subsubsection{Seed mass}

We first note that unlike the other parameters investigated in this study, seed mass has been resolved only at the genus level. This is potentially an issue as there are large genera present in this dataset (e.g. Pouteria, Ocotea and Eschweilera) within which there may be a rather broad variation in seed mass that has the potential to mask causative patterns reported here (C. Baraloto, personal communication, 2011). Nevertheless, as is evident from Fig. 1, seed mass varies by nearly five orders of magnitude which is much greater than the relative variability even in leaf area. Thus, although it must be accepted that any causative relationships may well have been stronger if seed mass had been more accurately determined, where relationships have been found in this data there is little reason to suspect that they are an artifact of our less than ideal species level measurements of $S$.

Bearing this in mind, we note that, as has been reported by others, seed mass showed significant positive correlations with both $H_{\max }$ (Fig. 3; Foster and Janson, 1985; Hammond and Brown, 1995; Kelly, 1995; Metcalfe and Grubb, 1995; Grubb and Coomes, 1997), and $\rho_{\mathrm{w}}$ (Fig. 4; ter Steege and Hammond, 2001), although the latter relationship was not detected by Wright et al. (2006), perhaps because of methodological issues (Williamson and Weimann, 2010). Generally speaking, a greater seed size should confer a greater ability for survival and thus tend to be favoured under less favorable environmental conditions such as deep shade or nutrient poor soils (Westoby et al., 2002; ter Steege et al., 2006). This readily provides a basis for indirect correlations between $S$ and wood/stem density to exist as high values of $\rho_{\mathrm{x}}$ or $\rho_{\mathrm{w}}$ are similarly associated with shade and/or dystrophic soil conditions (Sect. 4.1; Kitajima, 1994). More controversial is the basis of the relationship between $S$ and $H_{\max }$. For example, the suggestion of Moles et al. (2005) that, by analogy with Charnov's life history theory for mammals, larger statured species may have larger seeds because they require a longer juvenile period has been contested by Grubb et al. (2005) who maintain that it is simply the range of feasible seed sizes that a species can have that increases with $H_{\max }$. Moreover, for tropical trees at least, there is probably little correlation between juvenile period and $H_{\max }$, with faster-growing lowwood density pioneer type trees attaining greater heights than their smaller statured shade counterparts and in a shorter time (Baker et al., 2009). Indeed, by applying a general scaling model Falster et al. (2008) showed that longer juvenile periods alone are not sufficient to generate a correlation between height and seed size. They suggested that size-asymmetric 
competition among recruits (i.e. competition for light) may be the main factor having caused evolution towards larger offspring size. In this scheme of things, correlations with adult height come about because larger adults have a greater total reproductive output, thus generating more intense competition among recruits. That model tested dynamics only with a single species at a time, but it is likely to still apply in more complex species systems such as tropical forests, even though relative size at the onset of maturity is much more variable for tropical trees species than for animal systems (Thomas, 1996; Wright et al., 2005). We also consider it unlikely that simple physical constraints can account for much of the relationships (also seen in Fig. 3) as even small statured species can have reasonably large seeds and/or fruits (for example Theobromba, or many members of the genus Licania: Prance, 1972). Likewise, wind dispersed species have both small seeds and a tendency to occur in the upper canopy strata where higher wind velocities aiding dispersal are greater (Hughes et al., 1994), one obvious example from the Amazon Basin being the widespread neotropical species Jacaranda copaia (Jones et al., 2005).

As was also found by Wright et al. (2006), the study gives little support for one of "Corner's rules", viz. that due to their mutual dependence on the available supporting twig mass that leaf size and seed size should be positively correlated (Corner, 1949). There may be two reasons for this. First, as pointed out by Grubb et al. (2005) such biomechanical explanations would only be expected to apply where there is little flexibility in the number of fruits per inflorescence. Second, as for $\Phi_{\mathrm{LS}}$ (Fig. 5) the ratio of total leaf area to the supporting stem mass is to a large degree independent of $L_{\mathrm{A}}$ (Wright et al., 2007). Indeed, if anything, what our data suggest is that reproductive structures compete with leaves for available space as there is a nearly significant correlation between $\Phi_{\mathrm{LS}}$ and $S\left(r^{2}=-0.09, p=0.07\right)$ with this negative relationship significant for the low fertility species (Supplementary Information, Table 2). Thus, in contrast to vegetation types from more xeric habitats where leaf areas may be substantially constrained by hydraulic considerations, leaf area per unit available stem area or mass may actually be constrained by the requirements for simultaneous allocation of available carbohydrate to reproductive structures for most tropical forest trees. That being consistent with their tropical forest productivity being carbon limited as argued by Lloyd and Farquhar (2008).

Competition between foliage and developing fruit may also be the reason for the negative relationship between seed size and foliar $[\mathrm{Ca}]$ shown in Fig. 6, an observation also made for sub-tropical montane tree species by Easdale and Healey (2009). It has long been known that calcium is relatively immobile in plants (e.g., Kirby and Pilbeam, 1984) with high rates of calcium supply to developing fruit essential for cell wall development and for longer term maintenance of membrane integrity. Sufficient levels of calcium are also required to maintain the integrity of the fruit flesh includ- ing resistance to fungal attack even after abscissed from the plant (Bangerth, 1979). Due to its immobility, this calcium accumulation in fruit tissues must occur at the expense of the leaves, and thus Fig. 6 does not necessarily imply that $\mathrm{Ca}$ itself may be limiting for either reproductive tissue development or leaf physiological function. Indeed, the SMA slope fit of -8.3 suggests that for each doubling of $S$ foliar [Ca] declines by only about $10 \%$, a value roughly consistent with the similar [Ca] in both seed and leaf tissue (as evidenced from the seed data of Grubb and Coomes (1997)) and with about 0.1 of total South American tropical forest "soft" litterfall occurring as reproductive organs (Chave et al., 2010). Even though such a result does not, therefore, necessarily imply direct effect of Ca availability on tree function, it is interesting to note that species growing on extremely cation poor spodosols are characterised by relatively small seed masses as compared to more fertile nearby forests (Grubb and Coomes, 1997) as well as with leaf photosynthetic rates showing an apparent dependence of leaf calcium concentrations (Reich et al., 1995). Moreover, for forests on such nutrient poor soils, carbon allocation to photosynthetic organs is apparently prioritised over that to reproduction (Chave et al., 2010). This is consistent with neotropical forest reproductive structure frequency being highly sensitive to soil fertility as inferred (apparently) from soil nitrogen status (Gentry and Emmons, 1987), and markedly lower for forests growing on less fertile soils. Overall, these observations suggest, as also discussed in Sect. 4.1.2, that foliar and reproductive tissue development may be in direct competition for either carbon or available nutrients where soil fertility is low.

\subsection{Integration of structural and physiological traits}

Although an examination of the various bivariate relationships, as discussed in Sect. 4.1 has hopefully proved informative, it is also of additional interest to quantify the extent to which all the various traits examined coordinate in their variability as a whole. In this respect, PCA was considered the most appropriate approach, as the first dimension of a PCA analysis can also be considered (with data normalisations prior to analysis as undertaken here) as the multivariate equivalent of an SMA model fit (Warton et al., 2006). We therefore interpret Table 2 as indicating five discrete integrated trait dimensions of tropical tree function and with the relative importance of these effects varying between high and low fertility species. This interpretation is made even though some of the measured properties such as $M_{\mathrm{A}}$ and $\rho_{\mathrm{x}}$ are modelled as having significant contributions to several dimensions. This is argued as reasonable on two counts. First, variations in some of the traits measured may have different underlying causes. For example, changes in $M_{\mathrm{A}}$ may be a consequence of variations in leaf thickness, tissue density or both (Witkowski and Lamont, 1991; Niinemets, 1999; Poorter et al., 2009) and likewise, variations in $\rho_{\mathrm{x}}$ could reflect differences in the proportions of gas, air and 
dry matter content (for hydrated tissue) in a wide range of combinations (Poorter, 2008). Second, as selective pressures are multiple, it is quite likely that contrasting combinations of individual traits have evolved for different reasons.

\subsection{1 $Д_{P D J}$ : Leaf structural costs and lifespan}

Although it is often considered that the primary dimension of the leaf economic spectrum is that proposed by Wright et al. (2004) viz. systematic variations in rates of photosynthetic carbon acquisitions (dry weight basis) being linked with foliar dry-weight concentrations of nitrogen, phosphorus, $M_{\mathrm{A}}$ and leaf longetivity, our analysis found that $U_{1}$ (accounting for the greatest component of the total variation in the dataset) did not involve nitrogen at all, and was actually dominated by leaf cation concentrations and (of opposite sign) a low carbon content. We suggest that this dimension, ДDJ, $_{\text {, }}$ reflects different plant strategies in terms of leaf construction costs, with the tendency for low $M_{\mathrm{A}}$ in these leaves of high mineral content presumably attributable to a low tissue density associated with thinner, less lignified cell walls and with the higher cations content presumably also balanced by higher levels of organic acids (Poorter and de Jong, 1999). Such leaves also being with lower overall construction costs and less investment of phenols and other carbon rich compounds in defense (Poorter and Villar, 1997). Presumably associated with $Д_{\mathrm{PDJ}}$ are also variations in leaf water relations. For example, it seems reasonable to expect that, associated with lower levels of lignification and reduced tissue densities, would be relatively more flexible cell walls and a low bulk modulus of elasticity (Niinemets, 2001), also with the high cation concentrations, especially potassium making a substantial contribution (in association with organic acids) to leaf tissue osmotic potentials (Olivares and Medina, 1992). These attributes, combined with the likely relatively low allocation of carbon resources to defense associated compounds such as lignin and phenols suggests that in many ways leaves of species with high $Д_{\text {PDJ }}$ scores may be able to expand quite rapidly but also be shorter lived and with more "deciduous like" characteristics than their lower $Д_{\mathrm{PDJ}}$ counterparts (see also Sobrado, 1986).

\subsection{2 $\lambda_{R W}$ : an extension of the classic "leaf economic spectrum"}

Our second identified CPC, $Д_{\mathrm{RW}}$ is that usually considered to be the principal dimension of the leaf economic spectrum (Wright et al., 2004), some aspects of which have also been presented for tropical forest tree species (Sandquist and Cordell, 2007; Santiago and Wright, 2007; Fyllas et al., 2009; Baltzer and Thomas, 2010; Baraloto et al., 2010; Domingues et al., 2010). Although we did not measure the photosynthetic or respiratory components, our analysis does suggest that for tropical forest species, $L_{\mathrm{A}}$ should also be included as part of $Д_{\mathrm{RW}}$, effectively incorporating the relationships between $L_{\mathrm{A}}$ and foliar $[\mathrm{N}]$ and/or [P] status
(Fig. 6) within this dimension. Such an involvement of $L_{\mathrm{A}}$ in the classic resource acquisition/utilisation spectrum has also been suggested from a data analysis involving 29 subtropical montane tree species across 12 ha of permanent sample plots in Tucumán, Argentina (Easdale and Healey, 2009). Although not considered significant on the basis of penalty corrected $p$-values, correlations between leaf size and $[\mathrm{N}]$ and $[\mathrm{P}]$ of a similar strength to that reported here (and hence included as part of $Д_{\mathrm{RW}}$ ) were also reported for tropical forest leaves sampled across a range of soil substrates in French Guiana (Baraloto et al., 2010). They concluded, however, that $L_{\mathrm{A}}$ was not closely linked with either [N] or [P]. This could be for several reasons. First, their sampling strategy covered a range of (undefined) soil types and as discussed in Sect. 4.3, these are likely to have modulated foliar nutrient levels but not $L_{\mathrm{A}}$. Second, our sampling has covered a much wider range of environments and soils, presumably bringing wider species-level variation into the dataset as whole. Thirdly, our analysis shows the $L_{\mathrm{A}}$ is also an important component of $Д_{\mathrm{FW}}$. This means that considered in simple bivariate relationships such as with leaf size, relationships may be less clear than when examined in conjunction with additional covariates as done here.

Also identified as part of $Д_{\mathrm{RW}}$ was $\Phi_{\mathrm{LS}}$, this being consistent with the general trend of $\Phi_{L S}$ to increases with increasing $L_{\mathrm{A}}$ (Fig. 5d). Especially as there was little contribution of $\oslash$ to this dimension (Table 2), this suggests, other things being equal, that trees with a higher $\lambda_{\mathrm{RW}}$ should also have increased rates of water transport per unit $A_{S}$.

Also of note (though of lesser significance than the above) was the increase in both $M_{\mathrm{A}}$ and $[\mathrm{Mg}]$ with decreasing $Д_{\mathrm{RW}}$. The former is, of course, well documented and, for woody plants at least, seems to be associated with an increased foliar tissue density rather than changes in leaf thickness (Niinemets, 1999; Poorter et al., 2009) and with a concurrent reduction in photosynthetic nutrient efficiency when expressed on a dry weight basis (Niinemets, 1999; Domingues et al., 2010). One possibility to account for this is low internal conductances to $\mathrm{CO}_{2}$ transfer for higher $M_{\mathrm{A}}$ species (Lloyd et al., 1992; Syvertsen et al., 1995; Warren and Adams, 2006), as perhaps evidenced by a small but significant positive contribution in $\oslash$ to this dimension $(0.014 \pm 0.05$ : Table 2$)$. Alternatively, relatively more nitrogen being allocated to cell walls of low $\lambda_{\mathrm{RW}}$ species (Onoda et al., 2004; Takashima et al., 2004), much of which would be expected to be in the form of defense related proteins (Feng et al., 2009). The decrease in $[\mathrm{Mg}]$ with higher values of $Д_{\mathrm{RW}}$ does not seem to have been reported before and may be related to its role as a coordination compound within the chlorophyll molecule. This is because, in the absence of variation in the withincanopy light regime, leaf chlorophyll contents should be relatively conserved on an area (as oppossed to mass) basis ( $\mathrm{Ri}$ jkers et al., 2000, Lloyd et al., 2010), this giving rise to attendant reductions in mass based magnesium concentrations as $M_{\mathrm{A}}$ decreases. 


\subsection{3 $Д_{\mathrm{FW}}$ : tree height and light acquisition}

Unlike the previous two dimensions considered, $Д_{\mathrm{FW}}$ does not involve foliar nutrient concentrations, but incorporates into one dimension variations in $H_{\max }, \Phi_{\mathrm{LS}}, \oslash, M_{\mathrm{A}}$ and to a lesser extent $\rho_{\mathrm{x}}$. This linkage is most likely through the hydraulics/plant height considerations already discussed as part of Sect. 4.1.1 and 4.1.2. That is to say, as $H_{\max }$ increases, a suite of trait adjustments occur; these including a reduction in $\Phi_{\mathrm{LS}}$ with estimates of $\oslash$ also suggesting that leaves with a high $H_{\max }$ also tend to operate at a lower $c_{\mathrm{i}} / c_{\mathrm{a}}$. As it seems likely that the higher $M_{\mathrm{A}}$ with increasing $H_{\max }$ is mostly attributable to increased leaf/mesophyll thickness and hence increases in photosynthetic capacity per unit leaf area, $A_{\max }$ (Sect. 4.1.1), this reduction in $c_{\mathrm{i}} / c_{\mathrm{a}}$ may be attributable to stomatal capacity increasing less with $H_{\max }$ than should $A_{\max }$. Such a tendency to operate at a lower $c_{\mathrm{i}} / c_{\mathrm{a}}$ would also help to conserve water for species more likely to be higherup in the canopy and hence exposed to higher levels of insolation and an associated greater evaporative demand (Lloyd et al., 2010).

Although $H_{\max }$ was not determined in their study, many of the above measured and/or inferred traits, viz. $\Phi_{\mathrm{LS}}$ and $A_{\max }$, were found to co-vary in a similar manner as for $\AA_{\mathrm{FW}}$ across a range of tropical forest trees in Panama by Meinzer et al. (2008). Though in that case, variations in $\rho_{\mathrm{x}}$ were considered of key importance in terms of trait coordination, especially through linkages to plant hydraulic parameters such as $K_{\mathrm{S}}$. Our observed contribution of $\rho_{\mathrm{x}}$ is likewise significant $(-0.22 \pm 0.10)$, though as discussed in Sect. 4.1.1 taken across a wide range of species and sites the strong relationship between $\rho_{\mathrm{x}}$ and/or $\rho_{\mathrm{w}}$ and $K_{\mathrm{S}}$ as observed by Meinzer et al. (2008) and also in some other studies (e.g., Santiago et al., 2004a) may not necessarily always apply.

Interestingly, in contrast to $Д_{\mathrm{RW}}$, variations in $\Phi_{\mathrm{LS}}$ were not accompanied by commensurate changes in $L_{\mathrm{A}}$. Indeed, if anything, $L_{\mathrm{A}}$ tend to increase with decreasing $\Phi_{\mathrm{LS}}$ as $H_{\max }$ increases within $Д_{\mathrm{FW}}$. Thus, we find integrated together within $Д_{\mathrm{FW}}$ the tendency of potentially taller trees to have fewer but larger leaves than their more vertically challenged counterparts. But with a lower $\Phi_{L S}$ overall. This lower $\Phi_{\mathrm{LS}}$ presumably serves to help maintain favourable water relations by counteracting greater resistances in the hydraulic pathway for potentially taller trees. Nevertheless, along with a higher $\oslash$, this lower $\Phi_{\mathrm{LS}}$ must also serve to reduce overall rates of whole tree carbon gain such as otherwise might be expected on the basis of higher $A_{\max }$ and a greater probability of high levels of incoming radiation. This trade-off associated with a greater $H_{\max }$ may be one reason for the observation that light demanding species with a low $\rho_{\mathrm{w}}$ do not necessarily show higher above-ground growth rates than their more shade tolerant counterparts (Keeling et al., 2008).

\subsection{4 $Д_{T S}$ : large seeds at the expense of leaf area}

As mentioned in Sect. 4.1.3, a major factor in accounting for this trait dimension is the presence of many large seeded Fabaceae, especially on nutrient poor soils, for whom it turns out do not have as large a $\Phi_{\mathrm{LS}}$ as they would otherwise be expected to have on the basis of their other trait values. Thus species with a high $Д_{T S}$ should best be regarded as those having a larger than average seed size with that being associated with a lower than average $\Phi_{\mathrm{LS}}$ as compared to trees of an equivalent $Д_{\mathrm{FW}}$ and/or $Д_{\mathrm{RW}}$. This lower $\Phi_{\mathrm{LS}}$ is also accompanied by reduction in $L_{\mathrm{A}}$ suggesting that it is not so much competition for lateral meristems (Kleiman and Aarssen, 2007) that gives rise to the negative association between $\Phi_{\mathrm{LS}}$ and $S$ within this dimension. But rather some sort of mechanical constraint such as the total mass capable of being borne per unit stem weight (Westoby and Wright, 2003) or a simple competition for carbon as discussed in Sect. 4.1.2.

The small but significant contributions of $M_{\mathrm{A}},[\mathrm{N}]$ and [P] to $A_{\mathrm{TS}}$ may be mostly genetic associations as members of the typically large seeded Fabaceae typically have a lower $M_{\mathrm{A}}$ and higher $[\mathrm{N}]$ and $[\mathrm{P}]$ than members of other plant families (Fyllas et al., 2009). On the other hand, as is discussed in Sect. 4.1.3, the lower foliar [Ca] levels associated with larger seed size is probably functionally linked though high calcium requirements of developing fruits and seeds.

\subsection{5 $Д_{P F L}$ : shade tolerance and long-term viability}

The fifth dimension identified, viz. Д $_{\mathrm{PF}}$, includes a significant positive contribution of increased $M_{\mathrm{A}}$, presumably associated with a high tissue density (as oppossed to leaf thickness) and associated increased leaf toughness (Kitajima and Poorter, 2010) and with high [C] linked through higher than average levels of more reduced structural compounds such as lignin as well as the typically high $\mathrm{C}$-content defense related compounds such as tannins and phenols (Fine et al., 2006; Read and Stokes, 2006; Read et al., 2009). Also associated with this is a higher $\oslash$, which may be suggestive of a greater internal resistance to $\mathrm{CO}_{2}$ diffusion within the leaves of high tissue density woody species (Lloyd et al., 1992; Syvertsen et al., 1995; Warren and Adams, 2006). Interestingly, as well as these correlated leaf traits in this dimension there is the coordinated involvement of a lower $H_{\max }$. Species with strong weightings along this trait dimension are also characterised by larger seeds as would be expected for shade adapted trees (Sect. 4.1.3). Along with a small but significant contribution of $\rho_{\mathrm{x}}, Д_{\mathrm{PFL}}$ is thus strongly suggestive of a coordinated trait dimension associated with shade tolerance and longevity. Not surprisingly then, it seems to play a much greater role in accounting for the trait variations of species associated with low fertility as opposed to high fertility soils as indicated by the different values for the characteristic roots $\left(\lambda_{\text {low }}=698, \lambda_{\text {high }}=318\right.$, Table 2$)$. 


\subsubsection{Significance of integrated trait dimensions and their components}

Although it is axiomatic that, to be included in any of the above integrated dimensions, a trait would have had to have been measured, what is perhaps more subtle, is that the mix of suites of traits coming together on any one PCA (or CPC) axis is also dependent on what is not measured. For example, our differentiation of the first two components of the CPC analysis of Table 2, viz. $Д_{\mathrm{PDJ}}$ and $\mathrm{Д}_{\mathrm{RW}}$ occurred mainly as consequence of [C] varying positively with $M_{\mathrm{A}}$ for $Д_{\mathrm{PDJ}}$ (this being interpreted as less allocation of photosynthate to more reduced structural compounds such as lignin in low $M_{\mathrm{A}} /$ high cation leaves), but increasing with decreasing $M_{\mathrm{A}}$ within $\lambda_{\mathrm{RW}}$ (this likely being an effect of higher lipid contents in higher photosynthetic capacity leaves). If leaf [C] is omitted from the analysis, then these two dimensions actually collapse into the one due to the strong correlations between all of the cations, nitrogen and phosphorus and (negatively) $M_{\mathrm{A}}$ (results not shown). This seems likely to have been the case for the results of Easdale and Healey (2009) and Baraloto et al. (2010) where, along with $M_{\mathrm{A}}$, cations, nitrogen and phosphorus were all considered part of the one dimension.

It is thus clear, that in the presence of additional parameter measurements (for example direct determination of $K_{\mathrm{S}}$ ) our derived dimensions may well have been different. Nevertheless, as discussed above, all five identified Д relate in some way to previously identified trait groupings; though in some cases (as for example with $S$ and $M_{\mathrm{A}}$ in $Д_{\mathrm{PFL}}$ ) not previously specifically linked through the species dependent variancecovariance matrix. It would be of great interest to see how the identified trait combinations vary with phylogeny and if they trace back through evolutionary time as discrete combinations. Nevertheless, these ambitions may be confounded by traits such as $M_{\mathrm{A}}$ being significant in almost all dimensions. As discussed at the start of Sect. 4.2.6 this may be because variations in $M_{\mathrm{A}}$ can be surrogates for variations in tissue density, leaf thickness or both, and similarly from the discussion in Sect. 4.1.1 to 4.1.5 above, variations in [C], $\Phi_{\mathrm{LS}}, L_{\mathrm{A}}$ and $\oslash$ are all potentially attributable to a range of different underlying causes. It is also probably for this reason that considerable ambiguity exists between different studies in terms of the significance (or even the sign) of some bivariate relationships. For example, if the primary source of variation in $L_{\mathrm{A}}$ and $M_{\mathrm{A}}$ were to be in association with $Д_{\mathrm{FW}}$ (this being similar in many ways to the light acquisition axis identified by Zhang and Cao (2009) for dipterocarps growing in a Chinese common garden) then a positive association between $M_{\mathrm{A}}$ and $L_{\mathrm{A}}$ would be expected, with leaves of upper canopy trees being both larger and thicker than those for trees lower down in the canopy (as was found to be the case for temperate deciduous trees, for example, by Niinemets, 1998). On the other hand, where foliar $\mathrm{N}$ and/or $\mathrm{P}$ dry weight concentrations are the main source of variation via ${Д_{R W}}_{\text {, then a }}$ negative relationship between $M_{\mathrm{A}}$ and $L_{\mathrm{A}}$ would be expected to be observed as, for example, was found to be the case for a range of herbaceous angiosperms by Shipley (1995). Or, as was found in some cases by Pickup et al. (2005) we can predict that in some circumstances there should be no relationship between $L_{\mathrm{A}}$ and $M_{\mathrm{A}}$, for example where $Д_{\mathrm{PDJ}}$ is the primary source of variation in the latter (as $L_{\mathrm{A}}$ is effectively absent from this dimension). Indeed, although much touted as a fundamental plant trait (e.g., Poorter et al., 2009; Asner et al., 2011; Kattge et al., 2011) $M_{\mathrm{A}}$ seems to us to be too confounded a measurement to be practically useful in differentiating different plant growth strategies as evidenced by its contribution to the five $Д$ above. Future work would be better directed towards separate measurements of foliar tissue density and thickness as well as leaf dry matter content (Witkowski and Lamont, 1991; Wilson et al., 1999). It is probably because of its ambiguous nature that $M_{\mathrm{A}}$ does not seem to be as good a predictor of demographic rates as first thought, especially when comparisons are done across different sites (Poorter et al., 2008).

Our results give no support for the supposed "second dimension" of the leaf economics spectrum proposed by Baltzer and Thomas (2010). That study, primarily based on data from Bornean forest trees did, however, fail to differentiate between taxonomic versus soil effects on foliar properties as has been done here. And with their "second dimension" (hardly likely to be orthogonal to the first dimension in any case) most likely simply reflecting soil fertility effects on foliar [P] as already well documented by Fyllas et al. (2009) and considered further below.

\subsection{Coordinated trait responses to environmental variability}

As evidenced by the $0.3-0.4$ portion of the total variance associated with the $\Phi_{\mathrm{LS}}, \rho_{\mathrm{x}}$ and $\oslash$ "plot effect" terms (Fig. 2), values of all these traits are not independent of where a species is growing and with there being strong environmental correlations between $\rho_{\mathrm{x}}$ and all of $\log [\mathrm{N}], \log [\mathrm{P}], \log [\mathrm{Ca}]$ and $\log [\mathrm{K}]$. This results in this structural parameter aligning itself along with elemental concentrations (including [C] with a negative weighting) in the first environmental PCA axis, $\varphi_{1}$ (Table 4), which was itself closely correlated with a PCA of soil chemical and physical properties (Fyllas et al., 2009; Quesada et al., 2010). This dimension, relating to what seems to be a soil fertility mediated effect, bears some resemblance to $Д_{\mathrm{RW}}$ but with a more easily discernible effect on $\rho_{\mathrm{x}}$. As mentioned in Sect. 4.1.1, such a fertility effect on $\rho_{\mathrm{x}}$ has been seen before as mediated by soil phosphorus availability for eucalypt and mangrove (Thomas et al., 2005; Lovelock et al., 2006). Although working with Brazilian savanna trees, Bucci et al. (2006) found it was nitrogen (as opposed to phosphorus) fertilisation that induced changes in $\rho_{\mathrm{x}}$ and $K_{\mathrm{S}}$ and in their case with $\mathrm{N}$-fertilisation causing attendant increases in $\Phi_{\mathrm{LS}}$ not detected here (Table 4). 
It seems likely that higher foliar [P], especially in combination with the lower $M_{\mathrm{A}}$ also associated with $\varphi_{1}$ would give rise to higher photosynthetic rates on an area basis (Domingues et al., 2010; Mercado et al., 2011). Thus, with tropical forest tree hydraulics and photosynthetic capacity being closely linked (Brodribb and Field, 2000; Brodribb et al., 2002; Santiago et al., 2004a) the likely increase in $K_{\mathrm{S}}$ accompanying a decrease in $\rho_{\mathrm{x}}$ with improved nutrient status may serve to help maintain some homeostasis in leaf water relations, this offsetting the higher rates of water-use per leaf area that would be expected to accompany any increase in $\Psi_{1}$. This suggestion supported by the only modest contribution of $\oslash$ to this dimension (Table 4). As to how such a coordination could occur is currently not clear, although the greater rates of cambial activity in the wood of higher $P$ status trees giving rise to a lower $\rho_{\mathrm{x}}$ might be attributable through sugar signalling mechanisms (Rolland et al., 2006; Hölttä et al., 2010), this resulting in less secondary thickening of vessels walls and a higher conduit area (Thomas et al., 2005). Other elements may also be involved though, for example effects of calcium and/or potassium on sapwood cambial activity (Fromm, 2010).

The second integrated environmental response dimension identified, $y_{2}$, essentially represents an integration of previous observed foliar trait responses to precipitation, viz. increased $M_{\mathrm{A}},[\mathrm{C}]$ and $\oslash$ and decreased $[\mathrm{Mg}]$ as mean annual precipitation increases as detailed in Fyllas et al. (2009). Although this response to $P_{\mathrm{A}}$ seems at odds with the general observation from inter-species analyses that leaves of more arid environments should have a higher $M_{\mathrm{A}}$ and often with a higher $\oslash$ (Miller et al., 2001; Santiago et al., 2004b) as discussed by Fyllas et al. (2009) this tendency towards more structurally rigid leaves at higher $P_{\mathrm{A}}$ may reflect different populations of the same species having different characteristics according to their prevailing environment. An aligned interpretation is that as severe dry season water deficits become increasingly less of a driving force in determining leaf lifetimes, leaves of any given species become more "evergreen" in their structural characteristics. And indeed it is worth noting that the distinction between evergreen and deciduous phenologies for tropical forest trees is a somewhat arbitrary one (Brodribb and Holbrook, 2005; Williams et al., 2008). In such an interpretation, an increase in $\oslash$ with $P_{\mathrm{A}}$ could be interpreted as either a tendency towards more conservative stomatal behavior in evergreen species where the precipitation regime is not strongly seasonal (Lloyd and Farquhar, 1994) or, alternatively to an increased resistance to $\mathrm{CO}_{2}$ diffusion within higher $M_{\mathrm{A}}$ leaves due to a higher cell wall resistance (Syvertsen et al., 1995).

Although not emerging as any sort of integrated response through the PCA analysis of the derived environmental effects, the temperature responses of $[\mathrm{N}],[\mathrm{K}]$ and $\rho_{\mathrm{x}}$ are all also of note; these have already been considered separately by Fyllas et al. (2009) and Patiño et al. (2009).

\section{Conclusions}

Extending beyond a simple bivariate analysis approach, this study has separated environmental from taxonomic effects for a range of structural and physiological traits for Amazon forest trees then using Common Principal Component Analysis to reveal as many as five discrete integrated axes of taxonomic variation. The relative weightings of the axes varies between low and high fertility soil associated species. The first component (accounting for the highest proportion of the total variance in the dataset) was not the classic "leaf economic spectrum", but rather relates mostly to variations in leaf construction costs per unit dry weight. The leaf economic spectrum was the second most important dimension identified in terms of variance accounted for, with our results suggesting that it also involves differences in leaf size as well as in leaf area: sapwood area ratios. Our third dimension brings together several structural traits, including species specific maximum height, individual leaf areas, leaf mass per unit area and xylem density and leaf magnesium concentrations. The fourth and fifth dimensions were interpreted as relating to a seed size/leaf area trade-off and shade tolerance characteristics respectively.

Several traits, in particular leaf mass per unit area, foliar carbon content and xylem density had significant weighting on many axes of variation, this being attributed to their somewhat ambiguous "proxy" nature for a range of underlying and more fundamental plant physiological properties. In particular, variations in twig xylem density may arise as a consequence of differences in a range of different underlying phenomena and with its generally poor correlation with other plant traits suggesting that it may not be as good a proxy for plant hydraulic conductivity as once thought.

Significant effects of environment on many plant traits were also identified. Some of these integrated into discrete dimensions of variation and with discrete but different changes being associated with variations in soil fertility versus differences in mean annual precipitation. Whether these differences relate to strict "environmental effects" or reflect systematic patterns in intra-specific trait variation with soils and/or climate remains to be established.

\section{Supplementary material related to this article is available online at: http://www.biogeosciences.net/9/775/2012/ bg-9-775-2012-supplement.pdf.}


Acknowledgements. We thank our many South American collaborators, also involved in the work described in Fyllas et al. (2009) and Patiño et al. (2009), for help with logistics and practical help in the field. Much of the data collection phase of this work (2001-2004) was supported through the EU FP5 "LBACarbonsink" project with subsequent data analyses supported by funding through the UK Natural Environment Research Council "QUERCC" and "TROBIT" consortia. We also thank David Warton (University of New South Wales) for pointing out to us the possibilities of CPC analysis and Patrick Phillips (University of Oregon) for making his CPC model estimation and evaluation programs freely available. Shiela Lloyd assisted with manuscript preparation.

\section{Edited by: A. Arneth}

The service charges for this open access publication have been covered by the Max Planck Society.

\section{References}

Ackerly, D. D.: Functional strategies of chaparral shrubs in relation to seasonal water deficit and disturbance, Ecol. Monogr., 74, 2544, 2004.

Asner, G. P., Martin, R. E., Tupayachi, R., Emerson, R. Martinez, P., Sinca, F., Powell, G. V. N. Wright, S. J. and Lugo, A. E.: Taxonomy and remote sensing of leaf mass per area (LMA) in humid tropical forests, Ecol. Appl., 21, 85-98, 2011.

Augspurger, C. K.: Seedling survival of tropical tree species: interaction of dispersal distance, light gaps and pathogens, Ecology, 65, 1705-1712, 1984.

Baker, T. R., Phillips, O. L., Laurance, W. F., Pitman, N. C. A., Almeida, S., Arroyo, L., DiFiore, A., Erwin, T., Higuchi, N., Killeen, T. J., Laurance, S. G., Nascimento, H., Monteagudo, A., Neill, D. A., Silva, J. N. M., Malhi, Y., López Gonzalez, G., Peacock, J., Quesada, C. A., Lewis, S. L., and Lloyd, J.: Do species traits determine patterns of wood production in Amazonian forests?, Biogeosciences, 6, 297-307, doi:10.5194/bg-6297-2009, 2009.

Baltzer, J. L. and Thomas, S. C.: A second dimension to the leaf economics spectrum predicts edaphic habitat association in a tropical forest, PLoS ONE, 5, e13163, doi:10.1371/journal.pone.0013163, 2010.

Bangerth, F.: Calcium related disorders of plants, Ann. Rev. Phytopathol., 17, 97-122, 1979.

Baraloto, C., Paine, T. C. E., Poorter, L., Beauchene, J., Bonal, D., Domenach, A.-M., Hérault, B., Patiño, S., Roggy, J.-C., and Chave, J.: Decoupled leaf and stem economics in rain forest trees, Ecol. Lett., 13, 1338-1347, 2010.

Bates, D. and Sarkar, D.: Ime 4: Linear Mixed-Effects Models Using S4 Classes. R package version 0.999375-27, 2007.

Brodribb, T. J. and Field, T. S.: Stem hydraulic supply is linked to leaf photosynthetic capacity: evidence from New Caledonian and Tasmanian rainforests, Plant Cell Environ., 23, 1381-1388, 2000.

Brodribb, T. J. and Holbrook, N. M.: Leaf physiology does not predict leaf habit; examples from tropical fry forest, Trees, 19, 290-295, 2005.
Brodribb, T. J., Holbrook, N. M., and Gutiérrez, M. V.: Hydraulic and photosynthetic co-ordination in seasonally dry tropical forest trees, Plant Cell Environ., 25, 1435-1444, 2002.

Bucci, S. J., Goldstein, F. C., Meinzer, F. C. Scholz, A., Franco, A. C. and Bustamante, M. C.: Functional convergence in hydraulic architecture and water relations in tropical savanna trees: From leaf to whole plant, Tree Physiol., 24, 891-899, 2004.

Bucci, S. J., Scholz, F. G., Goldestein, G., Meinzer, F. V., Franco, A. C., Campanello, P. I., Villa Lobos-Vega, R., Bustamante, M., and Miralles-Wilhelm, F.: Nutrient availability constrains the hydraulic architecture and water relations of savanna trees, Plant Cell Environ., 29, 253-267, 2006.

Casper, B. B., Heard, S. B., and Apanius, V.: Ecological correlates of single-seededness in a woody tropical flora, Oecologia, 90, 212-217, 1992.

Cavaleri, M. A., Oberbauer, S. F., Clark, D. B., Clark, D. A., and Ryan, M. G.: Height is more important than light in determining leaf morphology in a tropical forest, Ecology, 91, 1730-1739, 2010.

Cavender-Bares, J. and Holbrook, N. M.: Hydraulic properties and freezing-induced cavitation in sympatric evergreen and deciduous oaks with contrasting habitats, Plant Cell Environ., 24, 1243 1256, 2001.

Cavender-Bares, J., Kitajima, K., and Bazzaz, F. A.: Multiple trait associations in relation to habitat differentiation among 17 Floridian oak species, Ecol. Monog., 74, 635-662, 2004.

Chao, K.-J., Phillips, O. L., Gloor, E., Monteagudo, A., TorresLezama, A., and Vásquez-Martínez, R.: Growth and wood density predict tree mortality in Amazon forests, J. Ecol., 96, 281292, 2008.

Chave, J., Coomes, D., Jansen, S., Lewis, S. L., Swenson, N. G., and Zanne, E. R.: Towards a worldwide wood economic spectrum, Ecol. Lett., 12, 351-366, 2009.

Chave, J., Navarrete, D., Almeida, S., Álvarez, E., Aragão, L. E. O. C., Bonal, D., Châtelet, P., Silva-Espejo, J. E., Goret, J.-Y., von Hildebrand, P., Jiménez, E., Patiño, S., Peñuela, M. C., Phillips, O. L., Stevenson, P., and Malhi, Y.: Regional and seasonal patterns of litterfall in tropical South America, Biogeosciences, 7, 43-55, doi:10.5194/bg-7-43-2010, 2010.

Coomes, D. A., Jenkins, K. L., and Cole, L. E. S.: Scaling of three vascular transport systems along gradients of nutrient supply and altitude, Biol. Lett., 3, 86-89, 2007.

Corner, E.: The Durian theory, or the origin of the modern tree, Ann. Bot., 13, 368-414, 1949.

Domingues, T. F., Meir, P., Feldpausch, T. R., Saiz, G., Veenendaal, E. M., Schrodt, F., Bird, M., Djagbletey, G., Hien, F., Compaore, H., Diallo, A., Grace, J., and Lloyd, J.: Co-limitation of photosynthetic capacity by nitrogen and phosphorus in West Africa woodlands, Plant Cell Environ., 33, 959-980, 2010.

Easdale, T. A. and Healey, J. R.: Resource-use-related traits correlate within population turnover rates, but not stem diameter growth rates in 29 subtropical montane tree species, Perspect. Plant Ecol. Evol. Syst., 11, 203-218, 2009.

Falster, D. S. and Westoby, M.: Leaf size and angle vary widely across species: what consequences for light interception?, New Phytol., 158, 509-525, 2003.

Falster, D. S. and Westoby, M.: Alternative height strategies among 45 dicot rain forest species from tropical Queensland, Australia, J. Ecol., 93, 521-535, 2005. 
Falster, D. S., Moles, A. T., and Westoby, M.: A general model for the scaling of offspring size and adult size, Amer. Nat., 172, 299-317, 2008.

Farquhar, G. D., Ehleringer, J. R., and Hubick, K. T.: Carbon isotope discrimination and photosynthesis, Ann. Rev. Plant Biol., 40, 503-537. 1989.

Feng, Y.-L., Lei, Y.-B., Wang, R.-F., Callaway, R. M., ValienteBanuet, A., Inderjit, Li, Y.-P., and Zheng, Y.-L.: Evolutionary tradeoffs for nitrogen allocation to photosynthesis versus cell walls in an invasive plant, P. Natl. Acad. Sci. USA, 106, 18531856, 2009.

Fine, P. V. A., Miller, Z. J., Mesones, I., Irazuzta, S., Appel, H. M., Stevens, M. H. H., Sääksjärvi, I., Schultz, J. C., and Coley, P. D.: The growth-defense trade-off and habitat specialization by plants in Amazonian forests, Ecology, 87, S150-S162, 2006.

Flury, B.: Common Principal Components and Related Multivariate Models, Wiley, New York, 1988.

Foster, S. A.: On the adaptive value of large seeds for tropical moist forest trees: a review and synthesis, Bot. Rev., 52, 260-299, 1986.

Foster, S. A. and Janson, C. T.: The relationship between seed size and establishment conditions in tropical woody plants, Ecology, 66, 773-780, 1985.

Fromm, J.: Wood formation in trees in relation to potassium and calcium nutrition, Tree Physiol., 30, 1140-1147, 2010.

Fyllas, N. M., Patiño, S., Baker, T. R., Bielefeld Nardoto, G., Martinelli, L. A., Quesada, C. A., Paiva, R., Schwarz, M., Horna, V., Mercado, L. M., Santos, A., Arroyo, L., Jiménez, E. M., Luizzão, F. J., Neill, D. A., Silva, N., Prieto, A., Rudas, A., Silviera, M., Vieira, I. C. G., Lopez-Gonzalez, G., Malhi, Y., Phillips, O. L., and Lloyd, J.: Basin-wide variations in foliar properties of Amazonian forest: phylogeny, soils and climate, Biogeosciences, 6 , 2677-2708, doi:10.5194/bg-6-2677-2009, 2009.

Fyllas, N. M., Lloyd, J., and Quesada, C. A.: Deriving plant functional types for Amazonian forests for use in vegetation dynamics models, Perspect. Plant Ecol. Evol. Syst., http://dx.doi.org/10.1016/j.ppees.2011.11.001, 2012.

Galwey, N. W.: Introduction to Mixed Modelling: Beyond Regression and Analysis of Variance, Wiley, Chichester, 2006.

Gentry, A. H. and Emmons, L. H.: Geographical variation in fertility, phenology, and composition of the understory of neotropical forests, Biotropica, 19, 216-227, 1987.

Givnish, T. J.: On the adaptive significance of compound leaves, with particular reference to tropical trees, in: Tropical Trees as Living Systems, edited by: Tomlinson, P. B. and Zimmermann, M. H., Cambridge University Press, Cambridge, UK, 351-380, 1978.

Givnish, T. J.: Comparative studies of leaf form: Assessing the relative roles of selective pressures and phylogenetic constraints, New Phytol., 106(Suppl.), 131-160, 1987.

Gonzalez, E. and Fisher, R. F.: Variation in selected wood properties of Vochysia guatemalensis from four sites in Costa Rica, Forest Sci., 44, 185-191, 1998.

Gower, J. C.: Some distance properties of latent root and vector methods used in multivariate analyses, Biometrika, 53, 325-338, 1966.

Grubb, P. J.: A reassessment of the strategies of plant which cope with shortages of resources, Perspect. Plant Ecol. Evol. Syst., 1, 3-31, doi:10.1078/1433-8319-00049, 1998.
Grubb, P. J. and Coomes, D. A.: Seed mass and nutrient content in nutrient starved tropical rainforest in Venezuela, Seed Sci. Res., 7, 269-280, 1997.

Grubb, P. J., Coomes, D. A. and Metcalfe, D. J.: Comment on A Brief History of Seed Size, Science, 310, 783-783, 2005.

Hammond, D. S. and Brown, V. K.: Seed size of woody plants in relation to disturbance, dispersal, soil type in wet neotropcial forests, Ecology, 76, 2544-2561, 1995.

Hernández, R. A. and Restrepo, G.: Natural variation in wood properties of Alnus acuminata grown in Colombia, Wood Fiber Sci., 27, 41-48, 1995.

Hölttä, T., Mäkinen, H., Nöjd, P., Mäkelä, A., and Nikinmaa, E.: A physiological model of softwood cambial growth, Tree Physiol., 30, 1235-1252, 2010.

Hollander, M. and Wolfe, D. A.: Nonparametric Statistical Methods, J. Wiley and Sons, New York, 1999.

Houle, D., Mezey, J., and Galpern, P.: Interpretation of the results of common principal components analyses, Evolution, 56, 433440, 2002.

Hughes, L., Dunlop, M., French, K., Leishman, M., Rice, B., Rogerson, L., and Westoby, M.: Predicting dispersal spectra: a minimal set of hypotheses based on plant attributes, J. Ecol., 82, 933-950, 1994.

Ishida, A., Nakano, T., Yazaki, K., Matsuki, S., Koike, N., Lauenstein, D. L., Shimizu, M., and Yamashita, N.: Coordination between leaf and stem traits related to leaf carbon gain and hydraulics across 32 drought-tolerant angiosperms, Oecologia, 156, 193-202, 2008.

Jones, F. A., Chen, J., Weng, G.-J., and Hubbell, S. P.: A genetic evaluation of seed dispersal in the neotropical tree Jacaranda copaia (Bignoniaceae), Amer. Nat., 166, 543-555, 2005.

Kattge, J., Díaz, S., Lavorel, S., Prentice, I. C., Leadley, P., Bönisch, G., Garnier, E., Westoby, M., Reich, P. B., Wright, I. J., Cornelissen, J. H. C., Violle, C., Harrison, S. P., van Bodegom, P. M., Reichstein, M., Soudzilovskaia, N. A., Ackerly, D. D., Anand, M., Atkin, O., Bahn, M., Baker, T. R., Baldocchi, D., Bekker, R., Blanco, C., Blonder, B., Bond, W., Bradstock, R., Bunker, D. E., Casanoves, F., Cavender-Bares, J., Chambers, J., Chapin, F. S., Chave, J., Coomes, D., Cornwell, W. K., Craine, J. M., Dobrin, B. H., Durka, W., Elser, J., Enquist, B. J., Esser, G., Estiarte, M., Fagan, W. F., Fang, J., Fernández, F., Fidelis, A., Finegan, B., Flores, O., Ford, H., Frank, D., Freschet, G. T., Fyllas, N. M., Gallagher, R., Green, W., Gutierrez, A. G., Hickler, T., Higgins, S., Hodgson, J. G., Jalili, A., Jansen, S., Kerkhoff, A. J., Kirkup, K., Kitajima, K., Kleyer, M., Klotz, S., Knops, J. M. H., Kramer, K., Kühn, I., Kurokawa, H., Laughlin, D., Lee, T. D., Leishman, M., Lens, F., Lenz, T., Lewis, S. L., Lloyd, J., Llusià, J., Louault, F., Siyan Ma, S., Mahecha, M. D., Manning, P., Massad, T., Medlyn, B., Messier, J., Moles, A., Müller, S., Nadrowski, K., Naeem, S., Niinemets, U., Nöllert, S., Nüske, A. , Ogaya, R., Oleksyn, J., Onipchenko, V. G., Onoda, Y., Ordoñez, J., Overbeck, G., Ozinga, W., Patiño, S., Paula, S., Pausas, J. G., Peñuelas, J., Phillips, O. L., Pillar, V., Poorter, H., Poorter, L., Poschlod, P., Proulx, R., Rammig, A., Reinsch, S., Reu, B., Sack, L., Salgado, B., Sardans, J., Shiodera, S., Shipley, B., Sosinski, E., Soussana, J.-F., Swaine, E., Swenson, N., Thompson, K., Thornton, P., Waldram, M., Weiher, W., White, M., Wright, S. J., Sönke, B., Zaehle, S., Zanne, A. E., and Wirth, Ch.: TRY - a global database of plant traits, Global. Change Biol., 17, 2905- 
2935, 2011.

Keeling, H. C., Baker, T. R., Monteagudo, A., Vasquez Martinez, R., and Phillips, O. L.: Contrasting patterns of diameter and biomass increment across tree functional groups in Amazonian forests, Oecologia, 158, 521-534, 2008.

Kelly, C. K.: Seed size in tropical trees: a comparative study of factors affecting seed size in Peruvian angiosperms, Oecologia, 102, 377-388, 1995.

Kenzo, T., Ichie, T., Watanabe, Y., Yoneda, R., Nonomiya, I., and Koike, T.: Changes in photosynthesis and leaf characteristics with tree height in five diperocarp species in a tropical rain forest, Tree Physiol., 26, 865-873, 2006.

King, D. A.: Load bearing capacity of understory treelets of tropical wet forest, Bull. Torrey Bot. Club, 114, 419-428, 1986.

Kirby, E. A. and Pilbeam, D. J.: Calcium as a plant nutrient, Plant Cell Environ., 7, 397-405, 1984.

Kitajima, K.: Relative importance of photosynthetic traits and allocation patterns as correlates of seedling shade tolerance of 13 tropical trees, Oecologia, 98, 419-428, 1994.

Kitajima, K. and Poorter, L.: Tissue-level leaf toughness, but not laminar thickness predicts sapling leaf lifespan and shade tolerance of tropical tree species, New Phytol., 186, 708-721, 2010.

Kleiman, D. and Aarssen, L. W.: The leaf size/number trade off in trees, J. Ecol., 95, 376-382, 2007.

Larjavaara, M. and Muller-Landau, H. C.:Rethinking the value of high wood density, Funct. Ecol., 24, 701-705, 2010.

Lichstein, J. W., Simons, T. R., Shriner, S. A., and Franzreb, K. E.: Spatial autocorrelation and autoregressive models in ecology, Ecol. Monogr., 72, 445-463, 2002.

Lloyd, J. and Farquhar, G. D.: ${ }^{13} \mathrm{C}$ discrimination during $\mathrm{CO}_{2}$ assimilation by the terrestrial biosphere, Oecologia, 99, 201-215, 1994.

Lloyd, J. and Farquhar, G. D.: Effects of rising temperatures and $\left[\mathrm{CO}_{2}\right]$ on the physiology of tropical forest trees, Phil. Trans. Roy. Soc. Lond., 363B, 1811-1817, 2008.

Lloyd, J., Syvertsen, J. P., Kriedemann,P., and Farquhar, G. D.: Low conductances for $\mathrm{CO}_{2}$ diffusion from stomata to the sites of carboxylation in leaves of woody species, Plant Cell Environ., 15, 873-889, 1992.

Lloyd, J., Patiño, S., Paiva, R. Q., Nardoto, G. B., Quesada, C. A., Santos, A. J. B., Baker, T. R., Brand, W. A., Hilke, I., Gielmann, H., Raessler, M., Luizão, F. J., Martinelli, L. A., and Mercado, L. M.: Optimisation of photosynthetic carbon gain and within-canopy gradients of associated foliar traits for Amazon forest trees, Biogeosciences, 7, 1833-1859, doi:10.5194/bg-71833-2010, 2010.

Lovelock, C. E., Ball, M. C., Choat, B., Engelbrecht, B. J. Holbrook, N. M., and Feller, M. C.: Linking physiological processes with mangrove forest structure: phosphorus deficiency limits canopy development, hydraulic conductivity and photosynthetic carbon gain in dwarf Rhizophora mangle, Plant Cell Environ., 29, 793-802, 2006.

McKean, J. W., Terpstra, J. T., and Kloke, J. D.: Computational rank-based statistics, WIREs Comput. Stat., 1, 132-140, 2009.

Maghsoodloo, S. and Laszlo Pallos, L.: Asymptotic behavior of Kendalls partial rank correlation coefficient and additional quantile estimates, J. Statist. Comput. Simul., 13, 41-48, 1981.

Malhado, A. C. M., Malhi, Y., Whittaker, R. J., Ladle, R. J., ter Steege, H., Phillips, O. L., Butt, N., Arag ao, L. E. O. C.,
Quesada, C. A., Araujo-Murakami, A., Arroyo, L., Peacock, J., Lopez-Gonzalez, G., Baker, T. R., Anderson, L. O., Almeida, S., Higuchi, N., Killeen, T. J., Monteagudo, A., Neill, D., Pitman, N., Prieto, A., Salomão, R. P., Vàsquez-Martnez R., and Laurance, W. F.: Spatial trends in leaf size of Amazonian rainforest trees, Biogeosciences, 6, 1563-1576, doi:10.5194/bg-61563-2009, 2009.

Malhado, A. C. M., Whittaker, R. J., Malhi, Y., Ladle, R. J., ter Steege, H., Phillips, O. L., Arag ao, L. E. O. C., Baker, T. R., Arroyo, L., Almeida, S., Higuchi, N., Killeen, T. J., Monteagudo, A., Pitman, N. C. A., Prieto, A., Salomão, R. P., VàsquezMartnez R., Laurance, W. F., and Ramìrez-Angulo, H.: Are compound leaves an adaptation to seasonal drought or to rapid growth? Evidence from the Amazon rain forest, Global Ecol. Biogeog., 19, 852-862, 2010.

Martinéz-Cabrera, M., Jones, H. I., Espino, C. S., Shenk, S., and Jochen, H.: Wood anatomy and wood density in shrubs: Responses to varying aridity along transcontinental transects, Am. J. Bot., 96, 1388-1398, 2009.

Meinzer, F. C., Campanello, P. I., Domec, J.-C., Gatti, M. G., Goldstein, G., Villalobos-Vega, R., and Woodruff, D. R.: Constraints on physiological function associated with branch architecture on wood density of tropical forest trees, Tree Physiol., 28, 16091617, 2008.

Mercado, L. M., Patiño, S., Domingues, T. F., Fyllas, N. M., Weedon, G. P., Sitch, S., Quesada, C. A., Phillips, O. L., Aragão, L. E. O. C, Malhi, Y., Dolman, A. J., Restrepo-Coupe, N., Saleska, S. R., Baker, T.R., Almeida, S., Higuchi, N., and Lloyd, J.: Variations in Amazon forest productivity correlated with foliar nutrients and modelled rates of photosynthetic carbon supply, Phil. Trans. R. Soc. B, 366, 3316-3329, 2011.

Metcalfe, D. J. and Grubb, P. J.: Seed mass and light requirements for regeneration in Southeast Asian rain forest, Can. J. Bot., 73, 817-826, 1995.

Miller, J. M., Williams, R. J., and Farquhar, G. D.: Carbon isotope discrimination by a sequence of Eucalyptus species along a subcontinental rainfall gradient in Australia, Funct. Ecol., 15, 222-232, 2001.

Moles, A. and Westoby, M.: Do small leaves expand faster than large leaves, and do shorter expansion times reduce herbivore damage?, Oikos, 90, 517-526, 2000.

Moles, A. T, Ackerly, D. D., Webb, C. O., Tweddle, J. C., Dickie, J. B., and Westoby, M.: A brief history of seed size, Science, 307, 576-80, 2005.

New, M., Lister, D., Hulme, M., and Makin, I.: A high-resolution data set of surface climate over global land areas, Climate Res. 21, 1-25, 2002.

Niinemets, U.: Are compound-leaved species woody species inherently shade tolerant? An analysis of species ecological requirements and foliar support costs, Plant Ecol., 134, 1-11, 1998.

Niinemets, U.: Components of leaf mass per unit area - thickness and density, alter leaf photosynthetic capacity in reverse directions in woody plants, New Phytol., 144, 35-47, 1999.

Niinemets, U.: Global scale climatic controls of leaf dry mass per unit area, density and thickness in trees and shrubs, Ecology, 82, 453-489, 2001.

Olivares, E. and Medina, E.: Water and nutrient relations of woody perennials from tropical dry forests, J. Veg. Sci., 3, 383-392, 1992. 
Omolodun, O. O., Cutter, B. E., Krause, G. F., and McGinnes, E. A.: Wood quality in Hidegardia berteri (Mast.) Kossern - An African tropical pioneer species, Wood Fiber Sci., 23, 419-435, 1991.

Onoda, Y., Hikosaka, K., and Hirose, T.: Allocation of nitrogen to cell walls decreases photosynthetic nitrogen-use efficiency, Funct. Ecol., 18, 419-425, 2004.

Patiño, S., Lloyd, J., Paiva, R., Baker, T. R., Quesada, C. A., Mercado, L. M., Schmerler, J., Schwarz, M., Santos, A. J. B., Aguilar, A., Czimczik, C. I., Gallo, J., Horna, V., Hoyos, E. J., Jimenez, E. M., Palomino, W., Peacock, J., Peña-Cruz, A., Sarmiento, C., Sota, A., Turriago, J. D., Villanueva, B., Vitzthum, P., Alvarez, E., Arroyo, L., Baraloto, C., Bonal, D., Chave, J., Costa, A. C. L., Herrera, R., Higuchi, N., Killeen, T., Leal, E., Luizão, F., Meir, P., Monteagudo, A., Neil, D., NúñezVargas, P., Peñuela, M. C., Pitman, N., Priante Filho, N., Prieto, A., Panfil, S. N., Rudas, A., Salomão, R., Silva, N., Silveira, M., Soares deAlmeida, S., Torres-Lezama, A., Vásquez-Martínez, R., Vieira, I., Malhi, Y., and Phillips, O. L.: Branch xylem density variations across the Amazon Basin, Biogeosciences, 6, 545-568, doi:10.5194/bg-6-545-2009, 2009.

Phillips, P. C. and Arnold, S. J.: Hierarchical comparison of genetic variance-covariance matrices I. Using the Flury hierarchy, Evolution, 53, 1506-1515, 1999.

Pickup, M., Westoby M., and Basden A.: Dry mass costs of deploying leaf area in relation to leaf size, Funct. Ecol., 19, 88-97, 2005.

Poorter, H. and Villar, R.: The fate of acquired carbon in plants: chemical composition and construction costs. edited by: Bazzaz, F. A., Grace, J., in: Plant Resource Allocation, San Diego, Academic Press, 39-72, 1997.

Poorter, H. and de Jong R.: A comparison of specific leaf area, chemical composition and leaf construction costs of field plants from 15 habitats differing in productivity, New Phytol., 143, 163-176, 1999.

Poorter, H., Niinemets, U., Poorter, L., Wright, I. J., and Villar, R.: Causes and consequences of variation in leaf mass per area (LMA): a meta-analysis, New Phytol., 182, 565-588, 2009.

Poorter, L.: The relationships of wood-, gas- and water fractions of tree stems to performance an life history variation of tropical trees, Ann. Bot., Ann. Bot., 102, 367-375, 2008.

Poorter, L. and Bongers, F.: Leaf traits are good predictors of plant performance across 53 rain forest species, Ecology, 87, 17331743, 2006.

Poorter, L. and Rozendaal, D. M. A.: Leaf size and display of thirtyeight tropical tree species, Oecologia, 158, 35-46, 2008.

Poorter, L., Bongers L., and Bongers F.: Architecture of 54 moist forest tree species: traits, trade-offs, and functional groups, Ecology, 87, 1289-1301, 2006.

Poorter, L., Wright, S. J., Paz, H., Ackerly, D. D., Condit, R., IbarraManríquez, G., Harms, K. E., Licona, J. C., Martínez-Ramos, M., Mazer, S. J., Muller-Landau, H. C., Penã-Claros, M., Webb, C. O., and Wright, I. J.: Are functional traits good predictors of demographic rates? Evidence from five neotropical forests, Ecology, 89, 1908-1920, 2008.

Poorter, L., McDonald, I., Alarcón, A., Fichtler, E., Licona, J.-C., Penã-Claros, M. M., Sterck, F., Villegas, Z., and Sass-Klaassen, U.: The importance of wood traits and hydraulic conductance for the performance and life history strategies of 42 rainforest tree species, New Phytol., 185, 481-492, 2010

Prance, G. T.: Chrysobalanaceae, Flora Neotropica, 9, 1-409. 1972.

Preston, K. A., Cornwell, W. K., and Denoyer, J.: Wood density and vessel traits as distinct correlates of ecological strategy in 51 California coast range angiosperms, New Phytol., 170, 807-818, 2006.

Putz, F. E., Coley, P. D., Lu, K., Montalvo, A., and Aiello, A.: Uprooting and snapping of trees: structural determinants and ecological consequences, Can. J. For. Res., 13, 1011-1020, 1983.

Quesada, C. A., Lloyd, J., Schwarz, M., Patiño, S., Baker, T. R., Czimczik, C., Fyllas, N. M., Martinelli, L., Nardoto, G. B., Schmerler, J., Santos, A. J. B., Hodnett, M. G., Herrera, R., Luizão, F. J., Arneth, A., Lloyd, G., Dezzeo, N., Hilke, I., Kuhlmann, I., Raessler, M., Brand, W. A., Geilmann, H., Moraes Filho, J. O., Carvalho, F. P., Araujo Filho, R. N., Chaves, J. E., Cruz Junior, O. F., Pimentel, T. P., and Paiva, R.: Variations in chemical and physical properties of Amazon forest soils in relation to their genesis, Biogeosciences, 7, 1515-1541, doi:10.5194/bg-7-15152010, 2010.

R Development Core Team: R: A Language and Environment for Statistical Computing, Foundation for Statistical Computing, Vienna, Austria, ISBN3-900051-07-0, 2010.

Read, J. and Stokes, A.: Plant biomechanics in an ecological context, Amer. J. Bot., 93, 1546-1565, 2006.

Read, J., Sanson, G. D., Caldwell, E., Clissold, F. J., Chatain, A., Peeters, P., Lamont, B. B., de Garine-Wichatitsky, M., Jaffré, T., and Kerr, S.: Correlations between leaf toughness and phenolics among species in contrasting environments of Australia and New Caledonia, Ann. Bot., 103, 757-767, 2009.

Reich, P. B., Ellsworth, D. S., and Uhl, C.: Leaf carbon and nutrient assimilation and conservation in species of different successional status in an oligotrophic Amazonian forest, Funct. Ecol., 9, 6576, 1995.

Reich, P. B., Walters, M. B., and Ellsworth, D. S.: From tropics to tundra: Global convergence in plant functioning, P. Natl. Acad. Sci. USA, 94, 13730-13734, 1997.

Rolland, F., Baena-Gonzalez, E., and Sheen, J.: Sugar sensing and signalling in plants: conserved and novel mechanisms, Ann. Rev. Plant Biol., 57, 675-709, doi:10.1146/annurev.arplant.57.032905.105441, 2006.

Romero, C. and Bolker, B. M.: Effects of stem anatomical and structural traits on responses to stem damage: an experimental study in the Bolivian Amazon, Can. J. For. Res., 38, 611-618, 2008.

Roque, R. M.: Effect of management treatment and growing regions on wood properties of Gmelina arborea in Costa Rica, New Forests, 28, 325-330, 2004.

Rozendaal, D. M. A., Hurtado, V. H., and Poorter, L.: Plasticity in leaf traits of 38 tropical tree species in response to light: relationships with light demand and adult stature, Funct. Ecol., 20, 207-216, 2006.

Russo, S. E., Jenkins, K. L., Wiser, S. K., Uriate, M., Duncan, R. P., and Coomes, D. A.: Interspecific relationships among growth, mortality and xylem traits of woody species from New Zealand, Funct. Ecol., 24, 253-262, 2010.

Sandquist, D. R. and Cordell, S.: Functional diversity of carbongain, water-use, and leaf-allocation traits in trees of a threatened lowland dry forest in Hawaii, Am. J. Bot., 94, 1459-1469, 2007. Santiago, L. S. and Wright, I. J.: Leaf functional traits of tropical 
forest plants in relation to growth form, Funct. Ecol., 21, 19-27, 2007.

Santiago, L. S., Goldstein, G., Meinzer, F. C., Fisher, J. B., Machado, K., Woodruff, D., and Jones, T.: Leaf photosynthetic traits scale with hydraulic conductivity and wood density in Panamanian forest canopy trees, Oecologia, 140, 543-550, 2004a.

Santiago, L. S., Kitajima, K., Wright, S. J., and Mulkey, S. S.: Coordinated changes in photosynthesis, water relations and leaf nutritional traits of canopy trees along a precipitation gradient in lowland tropical forest, Oecologia, 139, 495-502, 2004b.

Sarmiento, C., Patiño, S., Paine, C. E. P., Beauchêne, J., Thibaut, A., and Baraloto, C.: Within-individual variation of trunk and branch xylem density in tropical trees, Amer. J. Bot., 98, 140149, doi:10.3732/ajb.1000034, 2011.

Shipley, B.: Structured interspecific determinants of specific leaf area in 34 species of herbaceous angiosperms, Func. Ecol., 9, 312-319, 1995.

Sobrado, M. A.: Aspects of tissue water relations and seasonal changes of leaf water potential components of evergreen and deciduous species coexisting in tropical dry forests, Oecologia, 68, 413-416, 1986.

Sterck, F., van Gelder, H. A., and Poorter, L.: Mechanical branch constraints contribute to life-history variation across tree species in a Bolivian forest, J. Ecol. 94, 1192-1200, 2006.

Sungpalee, W., Itoh, A., Kanzaki, M., Sringeryuang, K., Noguchi, H., Mizuno, T., Teejunuk, S., Hara, M., Chaiudon, K., Yamakura, T., and Sornngai, A.: Intra-and interspecific variation in wood density and fine-scale spatial distribution of stand-level wood density in a northern Thai tropical montane forest, J. Trop. Ecol., 25, 359-370, 2009.

Swenson, N. G. and Enquist, B. J.: The relationship between stem and branch wood specific gravity and the ability of each measure to predict leaf area, Amer. J. Bot., 95, 516-519, 2008.

Syvertsen, J. P., Lloyd, J., McConchie, C., Kriedemann, P. E., and Farquhar, G. D.: On the site of biophysical constraints to $\mathrm{CO} 2$ diffusion through the mesophyll of thick hyperstomatous leaves, Plant Cell Environ., 18, 149-157, 1995.

Takahashi, K. and Mikami, Y.: A weak relationship between crown architectural and leaf traits in saplings of eight tropical rainforest species in Indonesia, J. Trop. Ecol., 24, 425-432, 2008.

Takashima, T., Hikosaka, K., Hirose, T.: Photosynthesis or persistence: Nitrogen allocation in leaves of evergreen and deciduous Quercus species, Plant Cell Environ. 27, 1047-1054, 2004.

ter Steege, H. and Hammond, D. S.: Character convergence, diversity, and disturbance in tropical rainforest in Guyana, Ecology, 82, 3197-3212, 2001.

ter Steege, H., Pitman, N. C. A., Phillips, O. L., Chave, J., Sabatier, D., Duque, A., Molino, J.-F., Prévost, M. F., Spichiger, R., Castellanos, H., Hildebrand, P., and Vásquez, R.: Continentalscale patterns of canopy tree composition and function across Amazonia, Nature, 443, 444-447, 2006.

Thioulouse, J., Chessel, D., Dolédec, S., and Olivier, J.: ADE4: a multivariate analysis and graphical display software, Stat. Comput., 7, 75-83, 1997.

Thomas, S. C.: Relative size at onset of maturity in rain forest trees: a comparative analysis of 37 Malaysian species, Oikos, 76, 145154, 1996

Thomas, S. C. and Bazzaz, F. A.: Asymptotic height as a predictor of photosynthetic characteristics in Malaysian rain forest trees, Ecology, 80, 607-1622, 1999.

Thomas, D. S., Montangu, K. D., and Conroy, J. P.: Why does phosphorus limitation increase wood density in Eucalyptus grandis seedlings?, Tree Physiol., 26, 35-42, 2005.

van Gelder, H. A., Poorter, L., and Sterk, F. J.: Wood mechanics, allometry and life-history variation in a tropical rain forest tree community, New Phytol., 171, 367-378, 2006.

Vander Willigen, C., Sherwin, H. W., and Pammenter, N. W.: Xylem hydraulic characteristics of subtropical trees from contrasting habitats grown under identical environmental conditions, New Phytol., 145, 51-59, 2000.

Warren, C. A. and Adams, M. A.: Internal conductance does not scale with photosynthetic capacity: implications for carbon isotope discrimination and the economics of water and nitrogen use in photosynthesis, Plant Cell Environ., 29, 192-201, 2006.

Warton, D. I., Wright, I. J., Falster, D. S., and Westoby, M.: Bivariate line-fitting methods for allometry, Biol. Rev., 81, 259-291, 2006.

Weber, J. C. and Montes, C. S.: Geographic variation in tree growth and wood density of Guazuma crinita Mart, in the Peruvian Amazon, New Forests, 36, 29-52, 2008.

Webb, L. J.: Environmental relationships of the structural types of Australia rain forest vegetation, Ecology, 49, 296-311, 1968.

Westoby, M. and Wright, I. R.: The leaf size-twig-size spectrum and its relationship to other important spectra of variation amongst species, Oecologia, 135, 621-628, 2003.

Westoby, M., Falster, D., Moles, A., Vesk, P., and Wright, I.: Plant ecological strategies: some leading dimensions of variation between species, Ann. Rev. Ecol. Syst., 33, 125-159, 2002.

Williams, L. J., Bunyavejchewin, S., and Baker, P. J.: Deciduousness in a seasonal tropical forest in western Thailand, Oecologia 155, 571-582, 2008.

Williamson, G. B. and Wiemann, M. C.: Measuring wood specific gravity... Correctly, Amer. J. Bot., 97, 207-215, 2010.

Wilson, P. J., Thompson, K., and Hodgson, J. G.: Specific leaf area and leaf dry matter content as alternative predictors of plant strategies, New Phytol., 143, 155-162, 1999.

Witkowski, E. T. F. and Lamont, B. B.: Leaf specific mass confounds leaf density and thickness, Oecologia, 88, 486-493, 1991.

Wright, I. R., Falster, D. S., Pickup, M., and Westoby, M.: Crossspecies patterns in the coordination between leaf and stem traits, and their implications for plant hydraulics, Physiol. Plant., 127, 445-456, 2006.

Wright, I. R., Ackerly. D. D., Bongers, F., Harms, K. E., IbarraManríquez, G., Martínez-Ramos, M., Mazer, S. J., MullerLandau, H. C., Paz, H., Pitman, N. C. A., Poorter, L., Silman, M., Vriesendorp, C. F., Webb, C. O., Westoby, M., and Wright, S. J.: Relationships among ecologically important dimensions of plant trait variation in seven Neotropical forests, Ann Bot., 99, 1003-1015, 2007.

Wright, I. J., Reich, P. B., Westoby, M., Ackerly, D. D., Baruch, Z., Bongers, F., Cavender-Bares, J., Chapin, T., Cornelissen, J. H., Diemer, M., Flexas, J., Garnier, E., Groom, P. K., Gulias, J., Hikosaka, K., Lamont, B. B., Lee, T., Lee, W., Lusk, C., Midgley, J. J., Navas, M. L., Niinemets, U., Oleksyn, J., Osada, N., Poorter, H., Poot, P., Prior, L., Pyankov, V. I., Roumet, C., Thomas, S. C., Tjoelker, M. G., Veneklaas, E. J., and Villar, R.: The worldwide leaf economics spectrum, Nature, 428, 821-827, 
2004.

Wright, S. J., Jaramillo, M. A., Pavon, J., Condit, R., Hubbell, S. P., and Foster, R. B.: Reproductive size thresholds in tropical trees; variations amongst individuals, species and forests, J. Trop. Ecol., 21, 307-315, 2005.

Yates, M. J., Verboom, G. A., Rebelo, A. G., and Cramer, M. D.: Ecophysiological significance of leaf size variation in Proteaceae from the Cape Floristic Region, Funct. Ecol., 24, 485-492, 2010.

Zach, A., Schuldt, B., Brix, S., Horna, V., Culmsee, H., Leuschner, C.: Vessel diameter and xylem hydraulic conductivity increase with tree height in tropical rainforest trees in Sulawesi Indonesia, Flora, 205, 506-512, 2010.
Zanne, A. R., Westoby, M., Falster, S., Ackerly, D. D., Loarise, S. R., Arnold, S. E. J., and Coomes, D. A.: Angiosperm wood structure: Global patterns in vessel anatomy and their relation to wood density and potential conductivity, Amer. J. Bot., 92, 207215, 2010.

Zhang, J.-L. and Cao, J.-F.: Stem hydraulics mediates leaf water status, carbon gain, nutrient efficiencies and plant growth rates across dipterocarp species, Funct. Ecol., 23, 658-667, 2009. 